\title{
DOCUMENTOS DO ARQUIVO HISTÓRICO DO RIO GRANDE DO SUL
}

(Correspondência Consular)

Com o fim de pôr ao alcance dos estudiosos da História Ibero-Americana fatos que possam ser de interesse para suas pesquisas, publicaremos a partir deste número a correspondência consular que existe no Arquivo Histórico do Estado do Rio Grande do Sul. Iniciando com a que se refere à Espanha, em sucessivos números incluiremos a de outros países que, desde o século XIX, mantiveram representação consular nessa parte do Brasil e de que se conservam documentos no referido arquivo.

Expressamos nossos mais sinceros agradecimentos ao diretor do Arquivo Histórico do Estado do Rio Grande do Sul, Moacir Domingues, pelo auxílio e facilidades que a toda hora nos tem proporcionado, sem o que não nos seria possível a execução desta tarefa.

A correspondência aqui incluída, em cópia paleográfica, foi recolhida pelos seguintes alunos do Curso de História do Instituto de Filosofia e Ciências Humanas da PUC/RS: Adelina Alves Garcia, Ana Maria P. Krause, Fernanda F. Schumacher, Gelsy Maria Prevedello, Jane Ermida Passuelo, Jary Almeida Berruti, Jussara Maria Pessato, Luiza Maria Binfaré Cezar, Maria Cristina B. Teixeira, Maria da Graça Freitas Torquato, Maria Graciosa Parisotto Ferreira, Maria Regina B. Castro, Marlise Hasenkamp e Wilson Sander, sob a direção do Professor Moacyr Flores. 


$$
\mathrm{III}^{\mathrm{mo}} . \mathrm{Ex}^{\mathrm{mo}} \text {. Sur }
$$

O abaixo assignado, Vice-Consul de S. M. C. nesta cidade tem a honra de fazer sentir a V. $\mathrm{Ex}^{\mathrm{ca}}$. que hontem foi prezo, e se acha abordo da canhoneira generoso Brasileiro o Marinheiro Pedro Uchoa da Nação Hespanhola: espera o abaixo assignado que S. Ex ${ }^{\text {ca }}$. expeça prompta ordem para que o mesmo seja solto, devolvendo-lhe o documento que ora junta.

Por esta occazião o abaixo assignado renova a $\mathrm{S}$. Ex ${ }^{\mathrm{Ca}}$. os protestos de sua estima, e consideração. Deos guarde a V. Ex ${ }^{\mathrm{ca}}$. muitos annos. Vice Consulado de S. M. C. em Porto Alegre 6 de Mayo de 1837.

IIImo Exmo Sñ̃. Feliciano Nunes Pires

Presidente desta Provincia.

Jozé Pereira da Costa

$$
\mathrm{III}^{\mathrm{mo}} . \mathrm{Ex} \mathrm{mo}^{\mathrm{Sn}} \text {. Sn. }
$$

$\mathrm{O}$ abaixo assignado Vice - Consul de S. M. C. nesta cidade, tem a honra de fazer saber a V. Ex ${ }^{\mathrm{ca}}$. que em Abril próximo passado foi prezo o Subdito Hespanhol D. Francisco Rio Fresco, por ordem do chefe de Policia, e depois mandou o por aí ordem do Juiz de Paz do $10^{\circ}$ Distrito, e não se the havendo formado até hoje processo, nem sendo possível, por não haver huã só testemunha, espera o abaixo assignado, que V. Ex ${ }^{\mathrm{ca}}$., uzando de sua authoridade, e em dezagravo da Justiça ultrajada se servirá das suas ordens afim de que o mencionado Subdito de S. M. C. seja posto em plena liberdade.

Deos guarde a V. Ex ${ }^{\mathrm{ca}}$. muitos annos.

Porto Alegre 23 de Junho de 1837.

$\mathrm{IIl}^{\mathrm{mo}} . \mathrm{Ex}{ }^{\mathrm{mo}}$. Sñ̃. Feliciano Nunes Pires

Prezidente desta Provincia. 


$$
\mathrm{IIl}^{\mathrm{mo}} \text {. Ex }{ }^{\mathrm{mo}} \text {. Snr. }
$$

O abaixo assignado Vice - Consul de S. M. C. nesta Cidade, tem a honra de reclamar de V. Ex ${ }^{\text {ca }}$. prompta, e efficaz providencia, para que seja desligado do serviço da Marinha que foi obrigado a tomar, o Subdito Hespanhol Carlos Raiz̃ Marinheiro, bem como, que seja, indemnizado do Salário, que venceu, durante o tempo de sua detenção abordo da Excuna Precioza Maria onde se acha presentemente.

Deos guarde a V. Ex ${ }^{\mathrm{ca}}$. Porto Alegre 11 de Julho de 1837.

Ill $^{\mathrm{mo}} . \mathrm{Ex}^{\mathrm{mo}}$. Snr. Feliciano Nunes Pires

Prezidente desta Provincia.

Jozé Pereira da Costa.

$$
\mathrm{Ill}^{\mathrm{mo}} \text {. e Ex }{ }^{\mathrm{mo}} \text {. Sn } \tilde{r} \text {. }
$$

O abaixo assignado Vice - Consul de S. M. Catholica nesta Cidade tendo alcançado de S. M. I. beneplacito para sem perda de seus direitos como Cidadão Brasileiro poder exercer suas funções nesta cidade se persuade de estar no gozo de todas as regalias e prerogativas como se fora Subdito de S. M.C. enesta supposição cuja decisão sujeita a opinião de V. Ex ${ }^{\mathrm{ca}}$. e lhe rogo se sirva de clarar=lhe por escripto para evitar contestações com o actual Juiz de Paz do $1 .^{\circ}$ Districto estando o abaixo assignado na posse das prerogativas que como Vice Consul lhe competem não pode ser compellido a tomar armas para serviço ordinario como acontece na Côrte do Imperio ondem ${ }^{\mathrm{mo}}$ em crise os vice Consules das diferentes Nações amigas nunca forão constrangidos atalfim ora para que V. Ex ${ }^{\text {ca }}$. mais bem orientado deste negócio possa decidir o abaixo assignado declara que apezar de todas as prerogativas que julga inherentes a seu cargo não cede nem por hum momento o terreno aqualquer $\tilde{\mathrm{q}}$ ouze impune pôr emduvida seu patriotismo e brasileirismo e para não se tornar mais enfadonho deixará de mencionar seus serviços a prol da Independencia deste Império sóm ${ }^{\text {te }}$ fallará dos q̃ tem prestado Voluntário á Integrid. $^{\mathrm{e}}$ do Imperio e por isso justo he saber V. $\mathrm{Ex}^{\mathrm{ca}}$. $\tilde{\mathrm{q}}$ no dia 15 de junho (o da reaccão) o abaixo assignado deixando por mão seu comodo, familia e interesses presserozo correu ao quartel do $8 .^{\circ}$ B. ${ }^{\mathrm{m}}$ e ahi se conservou até q̃ os rebeldes em gr. ${ }^{\mathrm{e}}$ massa no dia 30 m. ${ }^{\mathrm{mo}}$ mez se arremessarão contra o ponto da Brigadr. ${ }^{\mathrm{a}}$ então mui fraca a glória que deste conflicto the ressultou pelo denodo com $\tilde{q}$ alguns poucos patriotas que refrearão a audacia dos anarquistas assaz cunpensa seu sacrificio porque a intima conviç̧ão emq̃. está de que bem servio a patria the fas esquecer o risco que correra o m. ${ }^{\mathrm{mo}}$ lhe a conteceu no dia 20 de Julho em $\tilde{\mathrm{q}}$. os rebeldes segunda vez attacarão o intrincheiramento e depois desse a detenção do Brigadeiro Antero sempre o abaixo assignado tem prestado seu contigente voluntario e continuará o q̃. deseja he que o respectivo Juiz de Paz fique sabendo que direito nenhum tem para poder compellir o abaixo assignado e he por isso $\tilde{\mathrm{q}}$. o abaixo 
assignado roga a V. $\mathrm{Ex}^{\mathrm{ca}}$. se sirva declarar sua opinião arespeito. Por esta occasião o abaixo assignado faz a V. Ex ${ }^{\mathrm{ca}}$. os seus respeitozos cumprimentos. Deos guarde a V. Ex ${ }^{\mathrm{Ca}}$. muitos annos. Vice - Consulado de S. M. C. em Porto Alegre aos 13 de Outubro de 1837.

$\mathrm{IIl}^{\mathrm{mo}} . \mathrm{Ex}^{\mathrm{mo}}$. Snr. Feliciano Nunes Pires

Presidente desta Provincia.

Jozé Pereira da Costa

$$
\mathrm{IIl}^{\mathrm{mo}} \text {. Ex }{ }^{\mathrm{mo}} \text {. Snr' }
$$

O abaixo assignado Vice Consul de S. M. C. nesta Cidade tem a honra defazer chegar ao conhecimento de $\mathrm{V}^{\mathrm{a}} \mathrm{Ex}^{\mathrm{a}}$. o incluzo requerimento do Subdito Hespanhol João Faria dos Santos, cuja veracid ${ }^{\mathrm{e}}$. garanta por me achar habilitado $\mathrm{p}^{\mathrm{a}}$. isso: a sua rogativa he por natureza tão justa que eu me julgo dispensado de a demonstrar, esperando que $\mathrm{V}^{\mathrm{a}}$. $\mathrm{Ex}^{\mathrm{a}}$. de suas ordens arespeito: por esta occasião o abaixo assignado reitera a $\mathrm{V}^{\mathrm{a}}$. $\mathrm{Ex}^{\mathrm{a}}$. sua estima e consideração. Deos Guarde a $\mathrm{V}^{\mathrm{a}}$. Ex ${ }^{\mathrm{a}}$. Vice Consulado Hespanhol em Porto Alegre 4 de Maio de 1838.

Ill $^{\text {mo }}$. e Ex ${ }^{\mathrm{mo}}$. Snr Prezidente da Provincia

O Vice Consul

Jozé Pereira da Costa

$$
\mathrm{Ill}^{\mathrm{mo}} \text {. Snr. }
$$

O abaixo assignado Vice Consul de S. M. C. nesta Cidade se dirige a S. S. o Sní Secretario do Governo pela ausencia de S Ex ${ }^{a}$ o Snr. Prezidente da Provincia afim deque em nome do dito Snr'. se digne ordenar que sejaõ postos em plena liberdade os Subditos Hespanhoes que forão compellidos entrar no serviço das Canhoneiras, e por que como estrangeiros que são não possaõ ser compellidos a hum tal serviço, o abaixo assignado se convence que o Governo da Provincia de prompto reparará huã semelhante falta, bem como roga a devolução dos documentos juntos; aproveitando a occasião para assegurar a S. S., a sua estima e affeição.

Deos Guarde a S. S.

Porto Alegre 16 d' Outubro de 1838

III $^{\text {mo }}$. Sn' D. ${ }^{\text {or }}$ João Dias de Castro

Secretario do Governo

O Vice Consul de S.M.C. Jozé Pereira da Costa 
O abaixo assignado Vice Consul de S.M.C. com bastante desprazer conmunica a S.S. o Snr' Secretario do Governo que ve frustada a expectativa quetinha quando S.S. Tha annunciou em seu officio dactado de hoje em que lhe segnificou que de ordem de S. Ex ${ }^{\mathrm{a}}$. o Snr' Presidente da Provincia havia sido enviado ao Capitão de Fragata Parker para informar sobre a pertenção dos Subditos de S.M.C. cujos documentos de Nacionalidade forão prezentes a S.S. e de novo os envia para que conhecendo que de facto sao estrangeiros e não havendo sido engajados para o serviço Imperial, se torna urgente que independente de mais informação sejão postos em plena liberdade e esta urgencia cresce pela duplicada razão de ter de seguir a embarcação Canhoneira n. ${ }^{\circ} 5$ em q os mesmos se achão as oito horas da manhã o que o baixo assignado partecipa a S.S. afim de evitar que a violencia que os ditos Subditos de S.M.C. experimentão continue ou talvez se aumente rogando ao mesmo tempo a devolução dos documentos. A S.S. o Snr' Secretario do Governo renova o abaixo assignado sua consideração e respeito.

Deos Guarde a S.S. Vice Consulado Hespanhol em Porto Alegre

17 d' Outubro de 1838

Illmo. Snr. D ${ }^{\text {or }}$. João Dias de Castro

Secretario do Governo

O Vice Consul de S.M.C.

Jozé Pereira da Costa

III ${ }^{\mathrm{mo}}$. Snr'

Passo ás mãos de $\mathrm{V}^{\mathrm{a}}$. $\mathrm{S}^{\mathrm{a}}$. a incluza representação que neste momento me dirige o Subdito Hespanhol Carlos Raiz̃; pela leitura da mesma se conhece a primeira intenção a justiça de sua pertenção e a injustiça do $\mathrm{m}^{\mathrm{mo}}$ tempo com que se lhe denega o que pede, e a que inquestionavelmente não só tem todo o direito como ao contrário parece ser merecedor do reconhecimento, e não de huã protelaçaõ atoda a evidencia prejudicial a seus interesses, em consequencia pois eu rogo a $\mathrm{V}^{\mathrm{a}}$. $\mathrm{S}^{\mathrm{a}}$. se digne dar a este negocio o prompto desenvolvimento, como he de esperar de hum Delegado de hum Governo justiceiro. Renovo por esta occasião a $\mathrm{V}^{\mathrm{a}} \cdot \mathrm{S}^{\mathrm{a}}$. minha veneração. Deos guarde a Va. $\mathrm{S}^{\mathrm{a}}$. Vice Consulado Hespanhol em Porto Alegre 6 de Novembro de 1838. O vice consul de S.M.C.

Ilmo Snr. Doutor João Dias de Castro

Secretario do Governo da Provincia

Jozé Pereira da Costa 
Tenho a honra de offerecer a $V^{a}$. $S^{a}$. a incluza attestação do Comnı ${ }^{e}$. do Forte $n^{0}$, onde se vê, que Carlos Rodrigues Subdito de S.M.C. voluntariamente se alistou ao serviço do dito forte, sem prazo algum de tempo detreminado, e como os interesses do dito Subdito Hespanhol, hoje o obriguem a não continuar em semelhante serviço, e mesmo não havendo lei alguã coercitiva arespeito, não só lhe não convem, como positivamente ellenão quer, em consequencia eu julgo, que $\mathrm{a} \mathrm{V}^{\mathrm{a}} \cdot \mathrm{S}^{\mathrm{a}}$. compete por termo a huã contenda, que nada tem de agradavel para o Governo de S.M. o Subdito de S.M.C. fez mais, que o que lhe cumpria, constrangelo a continuar hum serviço do qual está exempto, he huma violação manifesta do Direito das Gentes.

Deos guarde a $\mathrm{V}^{\mathrm{a}}$. $\mathrm{S}^{\mathrm{a}}$. Vice Consulado Hespanhol em Porto Alegre aos 13 de Novembro de 1838

Ill $^{\text {mo }}$. Snr'. Doutor João Dias de Castro

Secretario do Governo

O Vice Consul de S.M.C.

Jozé Pereira da Costa.

$$
\mathrm{Ill}^{\mathrm{mo}} \text {. } \mathrm{Ex}^{\mathrm{mo}} \text {. Snr. }
$$

Abordo da Canhoneira n5 hoje surta neste Porto se achão dous Subditos de S.M.C. Gabriel Materell, e Gregorio Bermues que a mezes andão constrangidos ao serviço Imperial, e porque como Estrangeiros não possão ser compellidos a hum tal serviço e nem se achem ligados por engajamento algum he o motivo porque suplico a $\mathrm{V}^{\mathrm{a}} \cdot \mathrm{Ex}^{\mathrm{a}}$. se digne ordenar que sejão postos em plena liberdade. $\mathrm{V}^{\mathrm{a}} \cdot \mathrm{Ex}^{\mathrm{a}}$. terá a bondade devolver-me os documentos incluzos. Oabaixo assignado aproveita esta occasião para saudar a S.Ex ${ }^{\mathrm{a}}$.e assegurar-lhe sua estima, e consideração. Deos Guarde a $\mathrm{V}^{\mathrm{a}}$. Ex. ${ }^{\mathrm{a}}$ muitos annos. Vice Consulado Hespanhol em Porto Alegre aos 20 de $\mathrm{Fevr}^{\mathrm{O}}{ }^{\text {. de }} 1839$

III $^{\text {mo. }} \mathrm{Ex}^{\text {mo. }}$ Snr. Presidente e

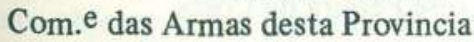

O Vice Consul de S.M.C.

Jozé Pereira da Costa 


$$
\text { Ill. }{ }^{\mathrm{mo}} \mathrm{Ex}^{\mathrm{mo}} \mathrm{S} .^{\mathrm{n}}
$$

O abaixo assignado, Cidadão Brasileiro, e por beneplacito Imperial, Vice Consul de S.M.C. nesta Cidade, tendo noticia certa de quealguns dos Vice Consules de Naçoens estrangeiras residentes nesta Cidade, igualmente Cidadoens Brasileiros, tem obtido do Governo Imperial dispensa do serviço da Guarda Nacional, entende por conseguinte o abaixo assignado, que tal deferencia lhe deve ser extensiva, não só por ser de direito como pela convicção em que está da imparcialidade e justiça administrativa de $\mathrm{V}^{\mathrm{a}}{ }^{\mathrm{Ex}}{ }^{\mathrm{a}}$, , pelo que espera que $\mathrm{V} .^{\mathrm{a}}{ }^{\mathrm{E}} \mathrm{Ex} .^{\mathrm{a}}$ dê as necessarias providencias conducentes ao fim a que se dirige o abaixo assignado, que todavia voluntariamente promete ser dos primeiros, como Cidadão Brasileiro a acudir ao chamamento da Patria, quando ella careça de seus Filhos, como por muitas vezes tem feito. Deos Guarde a V ${ }^{\mathrm{a}}$ Ex. ${ }^{\mathrm{a}}$ muitos annos.

Vice Consulado Real de Hespanha em Porto Alegre aos 14 de Janeiro de 1841.

Ill. ${ }^{\mathrm{mo}}$ Ex. ${ }^{\mathrm{mo}}$ Snr' Francisco Alves Machado

Presidente da Provincia

O Vice Consul de S.M.C. Jose Pereira da Costa

$$
\text { III. }{ }^{\mathrm{mo}} \text { Ex. }{ }^{\mathrm{mo}} \text { Snr.' }
$$

No officio que hoje tive a honra de dirigir a $\mathrm{V} \cdot{ }^{\mathrm{a}} \mathrm{Ex} \cdot{ }^{\mathrm{a}}$ me escapou no momento de o copiar de incluir os dous documentos que no mesmo menciona do que espero V. ${ }^{\mathrm{a}} \mathrm{Ex}^{\mathrm{a}}{ }^{\mathrm{a}}$ desculpará. Deus guarde a V. ${ }^{\mathrm{a}} \mathrm{Ex} \cdot{ }^{\mathrm{a}}$ muitos annos. Vice Consulado Real de Hespanha em Porto Alegre aos 21 de Agosto de 1841.

III. $^{\mathrm{m}}$ Ex. ${ }^{\mathrm{m}}$ Snr.' Doutor

Saturnino de Souza e Oliveira

Presidente da Provincia

O Vice Consul d S.M.C. José Pereira da Costa 


$$
\text { Ill. }{ }^{\mathrm{mo}} \text { e Ex. }{ }^{\mathrm{mo}} \mathrm{Snr} \text {.' }
$$

Tendo sido prezo hontem de manhã pela Policia os subdicos de S.M. Catholica Manoel Dias, e Vicente Ramon, aquelle caixeiro de uma caza de negocio, e este há poucos dias chegado do Rio Grande e pertendendo seguir sem demora para Montevideo, na qualidade de Vice Consul da nação Hespanhola, e por conseguinte obrigado a fazer valer seus direitos, tenho a honra de dirigir-me respeitozamente a V. ${ }^{\mathrm{a}} \mathrm{Ex}^{\mathrm{a}}{ }^{\mathrm{a}}$, afim de ponderar, que nenhuma circunstancia parece concorrer em desabono dos mencionados individuos pois que como já expuz o primeiro se acha estabelecido e o segundo chegado ha pouco, nada me consta haverem praticado, que lhes provocasse a prizão que soffrem, e ainda quando commetessem algum delicto outro deveria ser o procedimento a respeito, não sendo prezos, como não forão em flagrante.

A vista do exposto, da rectidão de V. ${ }^{a}$ Ex. ${ }^{a}$ espero haja de dar as convenientes ordens para que os referidos Manoel Dias e Vicente Ramon sejão relaxados da prizão, ou alias que se lhes faculte os meios de defeza que pela legislação do pais são outhorgados a todos os cidadoens Nacionais ou Estrangeiros, e isto com a necessaria urgencia, visto que a serem elles, como julgo, innocentes, hum momento de prizão he huã violencia, a qual de certo não pode obter o assenço de $\mathrm{V}^{\mathrm{a}}{ }^{\mathrm{Ex}}{ }^{\mathrm{a}}{ }^{\mathrm{a}}-\mathrm{V} \cdot{ }^{\mathrm{a}} \mathrm{Ex}^{\mathrm{a}}{ }^{\mathrm{a}}$ se dignará devolver-me os incluzos documentos. Deus Guarde a V. ${ }^{\mathrm{a}}$ Ex. ${ }^{\mathrm{a}}$ muitos annos. Vice Consulado Real de Hespanha em Porto Alegre aos 21 d' Agosto de 1841.

Ill. ${ }^{\text {mo }}$ e Ex. ${ }^{\text {mo }}$ Doutor Saturnino de Souza

e Oliveira, Presidente desta Provincia

O Vice Consul de S.M.C.

José Pereira da Costa

$$
\text { Ill. }{ }^{\mathrm{mo}} \text { e Ex. }{ }^{\mathrm{mo}} \text { Snr.' }
$$

Tendo eu a honra de expor a V. Ex ${ }^{\mathrm{a}}$ em officio de 24 do corrente mez algumas considerações pelas quaes sollicitava a soltura dos subditos Hespanhoes Manoel Dias e Vicente Ramon não recebi até hoje resposta de V. Ex. ${ }^{\mathrm{a}}$, e porque elles continuem a soffrer hua prizão injusta pois que os considero innocentes a vista do que a V. Ex. ${ }^{a}$ relatei, a qual thes importa transtorno e privaçoens incalculaveis, ouzo lembrar a V.Ex. ${ }^{a}$ este objecto que me parece de grande entidade e que sem duvida teria ja sido por V. Ex. ${ }^{a}$ resolvido se não obstassem outro de maior monta a que V. Ex. ${ }^{a}$ tem de acudir.

Attentas as disposiçoens amigaveis do Governo do Imperio com o do Reino da Hespanha, e o nimio empenho que se tem mostrado em attrahir braços livres para este pais, e attenta outro sim a rectidão de V. Ex. ${ }^{\mathrm{a}}$ conto certo com hua deliberação favoravel 
aos mencionados individuos, a quem já mais deffenderia, se me convencessem serem elles criminozos. Deos Guarde a V. ${ }^{\mathrm{a}}$ Ex. ${ }^{\mathrm{a}}$. Vice Consulado Real de Hespanha em Porto Alegre aos 28 de Agosto de 1841 .

III. ${ }^{\mathrm{mo}}$ e Ex. ${ }^{\mathrm{mo}}$ Doutor Saturnino de Souza e Oliveira

Presidente desta Provincia

O Vice Consul de S.M.C.

José Pereira da Costa

$$
\text { III. }{ }^{\mathrm{mo}} \text { Ex. }{ }^{\mathrm{mo}} \text { Snr.' }
$$

Tenho a honra levar ao conhecimento de V. ${ }^{a}$ Ex. ${ }^{a}$ que abordo da Canhoneira denominada Legalidade se acha com praça de marinheiro José Nunez, natural de Málaga subdito de S.M.C. e me diz achar-se constrangido neste serviço em consequencia forçozo me hé solicitar de $\mathrm{V} .{ }^{\mathrm{a}}{ }^{\mathrm{Ex}}{ }^{\mathrm{a}}$ se digne ordenar que seja posto em plena liberdade á qual tem direito incontestável. V. ${ }^{\mathrm{a}}$ Ex. ${ }^{\mathrm{a}}$ se dignará mais devolverme o incluzo documento que comprova sua Nacionalidade.

Deos Guarde a V ${ }^{\mathrm{a}}$. $\mathrm{Ex}^{\mathrm{a}}{ }^{\mathrm{a}}$ muitos annos.

1841.

Vice Consulado Real de Hespanha em Porto Alegre aos 18 d' Outubro de

III. ${ }^{\mathrm{mo}}$ Ex. ${ }^{\mathrm{mo}}$ Snr' Doutor

Saturnino de Souza Oliveira

Presidente d'esta Provincia

O Vice Consul de S.M.C.

José Pereira da Costa 
Ilm. ${ }^{\circ}$ e Ex ${ }^{\mathrm{mo}}$ Señr Prezidente

O abaixo assignado, Vice Consul de S.M. Catholica em Rio Grande, querendo gozar do mesmo indulto dos Avizos expedidos da Secretaria dos Negocios Estrangeiros, que ultimamente V.Ex. ${ }^{a}$ tem recebido, respeito a diversos Vice-Consules nesta Provincia, para o fim de sere izentos da Guarda Nacional, vem perante V.Ex. ${ }^{a}$ representar que a exemplo dos mais haja por bem expidir as suas ordens para que, o abaixo assignado a exemplo dos mais V" Consules seja izento do mencionado Servisso.

Deus Guarde a V. Ex ${ }^{\mathrm{a}}$ como ha mister.

Porto Alegre 13 de janeiro de 1841

$\mathrm{Il}^{\mathrm{mo}} \mathrm{Ex}^{\mathrm{mo}}$ Senr $\tilde{F}$ Francisco Alvares Machado

Prezidente da Provincia

\author{
J. J. dos $S^{\text {tos }}$ Ferr. $^{\mathrm{a}}$ \\ V. Consul de S. M. Catholica \\ em Rio Grande
}

III. ${ }^{\mathrm{mo}} \mathrm{Ex} \cdot{ }^{\mathrm{mo}} \mathrm{Snr}$.

Em 18 do proximo passado me dirigi a V. Ex. ${ }^{a}$ sollicitando se dignasse mandar por em liberdade ao Subdito de S.M.C. José Nunez que se achava abordo da Escuna de guerra Legalidade e hoje ainda se acha constrangido no mesmo serviço.

He-do meu dever fazer ver a V. ${ }^{a}$ Ex. $^{a}$ que o subdito de S.M.C. não quer empregar-se em hum tal exercicio e exige a sua Guia para tratar de sua vida. V. ${ }^{a}$ Ex. ${ }^{a}$ se dignará não só ordenar se lhe passe Guia como reenviar-me o documento de sua Nacionalidade que juntei ao meu officio ja citado.

Deos Guarde a V. ${ }^{\mathrm{a}}$ Ex. ${ }^{\mathrm{a}}$ muitos annos.

Vice Consulado Real de Hespanha em Porto Alegre aos 2 de Novembro de 1841.

Ill. ${ }^{\mathrm{mo}}$ Ex. ${ }^{\mathrm{mo}}$ Snr.' Doutor

Saturnino de Souza Oliveira

Presidente da Provincia

O Vice Consul de S.M.C.

José Pereira da Costa 
Acha-se abordo do Vapor Fluminense a meses constrangido a servir como Marinheiro Francisco Antonio Subdito Espanhol que tendo por veses sollicitado do respectivo Comm. guia de de sembarque, e que sob frivolos pretextos se the tem denegado, a despeito mesmo do documento que appresenta, emque prova ser Estrangeiro, e que junto envio a V. Ex. ${ }^{\mathrm{a}}$ terá a bondade de devolverme: espera pois o abaixo assignado que V. Ex. ${ }^{\mathrm{a}}$ mandando por immediatam. ${ }^{\mathrm{e}}$ emplena liberdade o Subdito de S.M.C. providenciará para não repetirem casos identicos.

Sente o abaixo assignado vivo praser tendo apresentar a V. Ex. ${ }^{a}$ sues respeitos e consideração

Deos Guarde a V.Ex ${ }^{\mathrm{a}}$ muitos annos.

Vice Condado d' Espanha em Porto Alegre aos 30 d' Abril de 1845

III. ${ }^{\mathrm{mo}}$ Sn $\tilde{\text { C Conde de Caxias }}$

General, e Presidente desta Província

Ovice Commt. ${ }^{\text {e }}$ S.M.C.

José Pereira da Costa

$$
\text { III. }{ }^{\mathrm{mo}} \text { Ex. }{ }^{\mathrm{mo}} \mathrm{Sr} \text {. }
$$

Tendo importunado a V. ${ }^{\mathrm{a}}$ Ex. ${ }^{\mathrm{a}}$ no dia 30 do proximo passado sollicitando como me cumpria o desembarque do Vapor Fluminense onde se acha com praça de marinheiro o Subdito Hespanhol Francisco Antonio, cujo documento de Nacionalidade foi annexo ao officio que a $\mathrm{V}^{\mathrm{a}}$ Ex. ${ }^{\mathrm{a}}$ dirigi em dita dacta e que de novo rogo se sirva devolver-me, e por que o mesmo como estrangeiro não possa ser constrangido a continuar em hum serviço que repugna por isso, e porque o mesmo me fez saber que hoje ou amanhã a dita Barca segue viagem he duplo motivo para eu de novo rogar a V. ${ }^{a}$ Ex. ${ }^{a}$ se digne ordenar que o Subdito de S.M.C. seja posto em sua plena liberdade. Deus guarde a V. ${ }^{\mathrm{a}}$ Ex. $^{\mathrm{a}}$ Porto Alegre, 16 de Maio de 1845.

Ill. ${ }^{\mathrm{mo}}$ Ex. ${ }^{\mathrm{mo}} \mathrm{S} .{ }^{\mathrm{r}}$ Conde de Caxias

General de Presidente desta Provincia

O Vice Consul de S.M.C. José Pereira da Costa 


\section{III. ${ }^{\mathrm{mo}}$ Señ.}

Respondendo ao officio que em data de hontem V.S ${ }^{\mathrm{a}}$. me dirigio acompanhando outro, que devolvo, do Ex ${ }^{\mathrm{mo}}$. Senr Prezidente da Provincia e General mi Chefe do Exercito, acerca do marinheiro $=$ Francisco Antonio $=$ requisitado pelo Consul de S. M. Cathollica: cumpre-mi informar a V.S. ${ }^{a}$ que esse individuo si acha com praça abordo d'esta Barca, tendo-se engajado voluntariamente na Escuna Guahyba em $1 .^{\circ} \mathrm{de}$ Maio de 1843 para servir pelo tempo de seis mezes, e tendo sido passado d'aquela Escuna para hum Lanchão armado dele desertou em 24 de Novembro de 1844 e foi por isso capturrado em 12 de Janeiro d'este anno para bordo da referida Escuna d'onde passou para esta Barca; porem não tendo esse marinheiro documento algum por onde prove ser subdito Hespanhol, não posso exactamente $\mathrm{aV} \mathrm{S} \mathrm{S}^{\mathrm{a}}$ informar a sua naturalidade: e quanto o achar-se constrangido, tambem não vejo motivo algum para assim julgar pois que tem a mesma garantia que outro qualquer engajado voluntariamente, não obstante ter sido desertor.

Julgo assim responder ao officio de $\mathrm{V} \mathrm{S}{ }^{\text {a }}$

Deos Guarde a V S. ${ }^{\mathrm{a}}$

Bordo da Barca de Vapor Fluminense - surto em Porto Alegre 7 de Maio de 1845
Ill $^{\text {mo }}$ Sen ̃̃ Joaquim Manuel de Oliveira Figueredo
$\mathrm{Cap}^{\mathrm{m}}$ de Fragata Comm. ${ }^{\mathrm{e}}$ da Força Naval
Manoel Luis Per. ${ }^{a}$ da Cunha
$1 .^{\circ} \mathrm{T}^{\mathrm{e}} \mathrm{Comm}^{\mathrm{e}}$

$$
\text { Ill. }^{\text {mo }} \text { e Ex. }{ }^{\mathrm{mo}} \text { Sñr }
$$

Respondendo ao officio que a V.Ex. ${ }^{\mathrm{a}}$ se dignou dirigir-me em data de hontem, á cerca do marinheiro Francisco Antonio, reclamado pelo Vice-Consul de Sua Magentade Catholica como Subdito da sua Nação, tenho a honra de diser a V. Ex. ${ }^{a}$ que em data de 8 do corrente mez, por officio n. ${ }^{\circ} 18$, informei a V. Ex. ${ }^{a}$ a respeito do dito marinheiro, em cumprimento ao officio que V. Ex. ${ }^{a}$ se dignou dirigir em 5 do mesmo mez; de cuja informação ora mando segunda via.

Cumpre-me agora accrescentar, que não apresentando o marinheiro em questão documento algum que comprove o ser elle com effeito Subdito de Sua Magestade Catholica; e occorrendo ter sido já praça d'Armada Imperial, d'onde desertou; o mandei passar da Barca Fluminense para hum dos navios extacionados n'este porto, a fim de que 
elle possa provar sua nacionalidade. Deos Guarde a V. Ex. ${ }^{a}$ Bordo do Patacho Desterro em Porto Alegre, 18 de Maio de 1845.

$$
\begin{aligned}
& \text { Ill. }{ }^{\mathrm{mo}} \text { e Ex. }{ }^{\mathrm{mo}} \text { Sñr Conde de Caxias, } \\
& \text { Presid. }^{\mathrm{e}} \text { da Prov. }{ }^{\text {a }} \text {, o General em Chefe do Exercito }
\end{aligned}
$$

Joaquim Manoel de Oliveira Fegueiredo Cap. de Frag. ${ }^{\text {ta }}$ Com. das F.N.

$$
\text { Ill. }{ }^{\mathrm{mo}} \text { e Ex. }{ }^{\mathrm{mo}} \mathrm{Sn} \tilde{r}
$$

Em resposta ao officio que V. Ex. ${ }^{a}$ se dignou dirigir-me em data de 5 do corrente mez, á cerca do marinheiro Francisco Antonio que representa o Vice Consul de S. M. Catholica achar-se constrangido a servir a bordo da Barca de Vapor Fluminense. Tenho a honra de passar ás mãos de V. Ex. ${ }^{\mathrm{a}} \mathrm{o}$ incluso officio, que a respeito me dirigio o Commandante da referida Barca a quem mandei ouvir de cujo officio se deprehende que o referido marinheiro tendo sido capturado como desertor d'Armada, nunca pedio o seu desembarque por estrangeiro.

Deos Guarde a V. Ex. ${ }^{a}$

Bordo do Patacho Desterro em Porto Alegre, 8 de Maio de 1845.

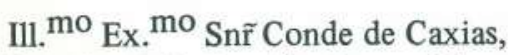
Presidente da Prov. ${ }^{\mathrm{a}}$ e General Comm. ${ }^{\mathrm{e}}$ em Chefe do Exercito

Joaquim Manoel d' Oliveira Figueiredo Cop. ${ }^{\mathrm{m}}$ de Frag. ${ }^{\text {ta }}$ com. $^{\mathrm{e}}$ das F. N. 
El ciudadano Español D. Martin Martinez en la mejor forma qua haya lugar en derecho y en su certidão de subdito de S.M. Catolica la Rieyna de España, ante V.S. parece y edice que habiendo salido dela ciudad de Montev. ${ }^{\circ}$ el 9 de Marzo de corr. ${ }^{\text {te }}$ año à virtud de las notorias circunstancias enticas en que se hallaba aquella plaza, $\mathrm{y}$ tratando de establecerme en esta ciudad del Rio Grande de S. ${ }^{n}$ Pedro del Sud, para ello y con este fin, embarqué en el Bergantin Goleta Americano Nacional ante en dicho puerto de Montevideo una factura de mercadorias (que en copia adjunto à esta solicitud) importante la cantidad de cinco mil trescientos setenta y cuatro pesos, dos y setenta centimos realy de nuestra moneda de plata; pero habiendo sufrido un fuerte temporal à la altura del parage denominado Castillos (en el Estado Oriental) nos fue forsoso arribar à aquella Costa, y como continuase el tiempo contrario por muchos dias, y no diste mucho aquel parage de esta Provincia, crei mas combeniente y assertado transportarme por tierra com mis efectos à esta ciudad. Como en dicho parage, a un que no del todo inhabitado, sea escaso de recursos no dejei de tocar algunas dificuldades para proporcionarme los medios de transportarme con mis efectos las que vencidas al cabo de pocas oras emprendí mi marcha conduciendo estos en dos carretas de bueyes que fletei al efeto. Ya tocaba el termino de mi ufanoso viage, pues me hallaba en el territorio de esta Provincia del Rio Grande y como dos leguas mas adentro del arroyo fronteiro denominado el Chui cuando se supo que habia tenido lugar un hecho de armas entre las fuerzas beligerantes en el indicado Estado Oriental, y cujas inmediatas consecuencias fueron aparecer por dicho parage una porcion de dispersos del Exercito que habia sido batido, y en seguimiento de estos un numero de menos conciderable delos victoriosos que ennardecidos enla persecucion, no solo violaran la linea de frontera sino que se adelantaran y derramaran como un torrente hasta por donde me hallaba yo tratando de continuar mi marcha. Confieso Señor Consul que mis circunstancias de viagero, Español mercador, y anciano, y mucho mas que todo el hallarme en un territorio neutral à las questiones politicas de un Estado estraño aun que vecino creia serian razones suficientes para exceptuarme deuna confiscacion absoluta de bienes tan inmerecida como arbitraria y atentatoria à las inmunidades del pais, que concideraba tener la fortuna de pisar. Pero bien à mi pesar ví que nada era capaz de garantirme de la capacidad de los soldados de la Confederación Argentina al mando de Gen. ${ }^{1}$ Oribe quienes se apoderou de mi pequeña fortuna el dia 30 del mismo mes de Marzo en el lugar preindicado sin mas título ni motibo que el uso de la fuerza bruta que no me era dado resistir. Dela perpetración de este atentado son vestigios y sabedores los señores, Comand. ${ }^{\text {te }}$ militar en aquella frontera entonces $D .{ }^{n} \mathrm{~N}$. Vargas, y el Juez de Paz de aquel distrito D. Jacinto Dias y ambos, como otros muchos vecinos podran deponer de la exactitud que marca esta sucinta narracion.

Habeindo, pues, sido despojado delos interezes com que ingrese à este País, y sometiendomé tan penosa circunstancia al denalliamento aun mas penoso, que es consegiente à ella, me hallo en la nesecidad de recurrir à la protección de V.S. para que conciderandomé en mi verdadero caracter de Ciudadano de una nacion cuja protección de interezes mercantiles é individuales le esta confiada qui era estenderme una mano venefactora poniendo en exercício el derecho de reclamacion, á quién competa, por el 
despojo violento q. ${ }^{\mathrm{e}}$ de mis interezes he padecido en donde menos lo esperaba, ni era de tenerse, en lo que desempeñará V.S. la honrosa misión de que sahalla incumbido en esta ciudad por parte del Gobiermo de S. Magestad Católica; y p. ${ }^{\mathrm{a}}$ ello.

A.V.S. - Pido y suplico que habiendomé por presentado con la adjunta copia del contenido de mi factura, se sirva provar lo combeniente, en lo que recivirá gracia en justicia

\section{MARTIN MARTINEZ}

Ex. ${ }^{\text {mo }}$ Sõr.

Haviendose justificado en este Vice Consulado demi cargo, Ser Español, Jose Frago que está al Servicio del Imperio del Brazil, hace seis años; y por el examen que letomé concusse ensu declaracion notener compromiso determinado, sinó hasta la conclusion dela guerra que huvo en esta Prov. ${ }^{a}$; la cual felismente concluida, no tiene dicho Frago voluntad deservir por mas tiempo: y haviendo reclamado los derechos que le curresponden comosubdito de S.M. Católica.

Porlo mismo, al dirigirme à V. Ex. ${ }^{\mathrm{a}}$, reconociendo su acostumbrada recta justicia; esperose dignará sea eliminado el mencionado Frago, del $1 .^{\circ}$ Cuerpo de Cavallería dela Guardia Nacional, à donde está sirviendo.

Tributo mis homenages à V.Ex. ${ }^{a}$ á quien Dios Guarde muchos años. Rio Grande 13 de Octubre de 1845.

IIl. ${ }^{\mathrm{mo}}$ y Ex ${ }^{\mathrm{mo}}$ Sor Conde de Caxías

Presidente y General en Gefe dela Provincia de Rio Grande del Sul.

Pablo de Goycoechea

Vice Consul 


\section{Ex. ${ }^{\mathrm{mo}}$ Sõr}

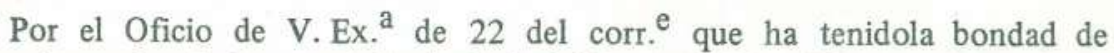
dirigirme, quedo enterado ha mandado dar baja del Servicio, á José Frago, subdito de Su Magestad Católica; conseguiente á mi reclamacion.

Por la fina atencion de V. Ex. ${ }^{a}$, le tributo las mas espresivas gracias.

Dios Guarde, á V. Ex. ${ }^{a}$ muchos años.

Rio Grande á 23 de Octubre de 1845.

Pablo de Goycoechea

Vice-Consul

Ex. ${ }^{\text {mo }}$ Sõr. Conde de Caxias

Presd. ${ }^{\mathrm{e}}$ y General en Gefe de la

Prov. $^{a}$ de Rio Gr. ${ }^{\text {e }}$ del Sur.

$$
\text { Ill. }{ }^{\text {mo }} \text { y Ex. }{ }^{\text {mo }} \text { Sõr. }
$$

En calidad de Vice Consul en esta Ciudad y en cumplimiento de los deberes que me están incumbidos, tomo la libertad de poner en conocimiento de V. Ex. ${ }^{a}$, los hechos consignados en el memorandun que acompañio, relativos á una escandalosa espoliacion cometida en el Territorio Brasileiro en 30 de Marzo, del corr. $^{e}$ año, por las fuerzas Argentinas, al mando del General Oribe, en perjuicio de un Ciudadano Español por nombre D. ${ }^{\mathrm{n}}$ Martin Martines.

Este individuo, reducido á un estado completo de penuria en consecuencia de este penoso acontecimiento; y procurando hoy obtener los documentos que le pueden servir para establecer la validad de sus reclamaciones: necesita de una declaracion auténtica de las personas mencionadas en el referido memorandun, y que fueron testigo, y son sabedores del atentado cometido, por cuyo motivo suplico la gracia de V. Ex. ${ }^{\mathrm{a}}$ para que, porla Secretaría del Gobierno, se sirva mandar expedir las ordenes necesarias p. ${ }^{a}$ obtener el Testimonio del Comand ${ }^{\text {te }}$ de Frontera de Chuy, el Sõr N. Vargas, y Juer de Paz, el Sõr Jacinto Dias, sobre los hechos siguientes.

Si es verdad que, en 30 de Marzo de 1845 fué esta Provincia invadida por una fuerza Argentina, al mando del General Oribe.

Si les consta que en aquella ocasion y hallandose el Ciudadano Español, $D^{n}$. Martin Martines en el Territorio Brasileiro cerca de dos leguas, de la linea divisoria con la Banda Oriental, fué él injusta y violentamente despojado por aquella misma fuerza, de la pequeña fortuna que traia consigo. 
Dignandose V. Ex ${ }^{\mathrm{a}}$. despues de haber recevido transmitirme el documento pedido, me hará en ello un obsequio particular, prestando V. Ex. ${ }^{a}$ un servicio importante á un Ciudadano Español victima de un acto de rapacidad y, revuelta.

El Ciudadano Español, D. Martin Martines, haviendo salido de Montevideo el 9 de Marzo del corr. ${ }^{e}$ año, en virtude de las notorias criticas circunstancias en que se hallava aquella Plaza; trató por consecuencia de establecerse en esta Ciudad del Rio Grande do Sul, para cuyo fin embarcó en el Bergantin Goleta Americano, Nahmakanta, en dicho puerto de Montevideo una factura de mercadorias, importando en 5,364 pesos plata 2 reales y 70 centesimos.

Por un fuerte temporal, sobre la altura de Castillos (en el Estado Oriental) les fué forzoso arribar a aquella Costa y como continuase el tiempo contrario por muchos dias y distando poco de esta Provincia, jusgó conveniente transportarse por tierra a esta Ciudad.

Como dicho lugar aunque nó de todo inhabitado, es algo escaso de recursos no dejó de esperimentar algunas dificuldades $\mathrm{p}^{\mathrm{a}}$ proporcionarse los medios de transportarse á esta Ciudad con sus efectos; pero vencidos al fin de los pocos dias que emprendió su marcha con dos carretas de bueyes que fletó p. ${ }^{\mathrm{a}}$ el efecto, y a tocaba el término de esta Prov. ${ }^{a}$ cosa de 2 leguas p. ${ }^{\mathrm{a}}$ adentro, del Arroyo limitrofe denominado Chuy; cuando se supo haber tenido lugar un hecho de armas entre las fuerzas contendentes en el indicado Estado Oriental cuyas proximas consecuencias fueron aparecer por dicho parage, una fuerza de dipersos del Exército que habia sido batido; y en seguida de estos un numero no menos considerable de los victoriosos que, entusiasmados no solamente en perseguirlos, sino tambien violando la linea de Frontera, se adelantaron, derramandose como un torrente hasta el lugar á donde se hallava el referido Martines que tratava de continuar su viage. Fué puer en esa ocasion y en el mencionado dia 30 de Marzo que los Soldados de la confederac. ${ }^{\mathrm{n}}$ Argentina al mando del General Oribe se apoderaron de la pequeña fortuna de dicho D. Martin Martines, sin mas titulo ni motivo si no el uso de la fuerza a que no le era dado resictir.

De semejante perpetracion, son testigos y sabedores los Srẽs. N. Vargas, Comandante militar de aquella Frontera y Jacinto Dias, Juez de Pas, de aquel Distrito; y tanto estos como otros muchos vecinos podrón Testimonar.

Tengo el honor de ser con la maior consideracion y respeto.

de 1845 .

De V. Ex. ${ }^{a}$ mui obsecuente y atento venerador. Rio Grande 29. de Octubre

Pablo de Goycoechea

Vice Consul

III ${ }^{\mathrm{mo}}$. y Ex. ${ }^{\mathrm{mo}}$ Sõr. Conde de Caxías

Presidente y General en Gefe, de la

Provincia de Rio Grande del Sur. . 


\section{Al Ex ${ }^{\mathrm{mo}}$ Sõr Presidente de la Provincia de Rio Grande del Sur Dón Manuel Antonio Galvão.}

El abajo firmado en calidad de Vice Consul de S.M. Católica y en cumplimiento de los deberes que le están incumbidos, se toma la libertad de poner en conocimiento deV.Ex. ${ }^{a}$ los documentos adjuntos. El n. ${ }^{\circ} 1$ se refiere al Oficio que dirijí con data de 14 deDiziembre 1846, al Sõr Juez Municipal, de Huerfanos y ausentes de la Ciudad de Pelotas, acompañadode los Documentos auténticados, relativos de mi reclamacion y que exĩsten en este Vice Consulado. Me tomopues la confianza de reproducirlos a V.Ex. ${ }^{\mathrm{a}}$, notados con los números $2,3,4,5$ y 6 .

Tambien con el $\mathrm{n} .{ }^{0} 7$, verá V. Ex. ${ }^{\mathrm{a}}$, copia dela recepcion de mi indicado Oficio $n .^{0} 1$; y aun hoy es el dia quenotengo contestacion?! Atribuía tal vez dicha circunstancia, á la causal de dias feriados, peroya pasados ellos; no se á queinferir la morosidad.

Dirigiendome á V. Ex. ${ }^{\mathrm{a}}$ y sometiendo este asunto á sua sabia penetracion, espero deque V. Ex. ${ }^{a}$, se dignará mandar dictar orden, para queyosea con la brevedad posible, no solamente, suficientemente enterado del estado de los bienes; sinó tambien el quede me entreguen libros, papeles y todolo depositado en dicha Ciudad, de la pertenencia del finado $D^{n}$. Antonio Vizet que murió abintestado en la mencionada Ciudad dePelotas em 1844, para los fines convenientes.

Como el arreglode la testamentaria de Vizet y toda operacion consiguinte, debe de hacerse en el Consulado General de España, en Montevideo; me repiten todavia el deseo de tener noticia del resultado dela pretencion. Espero deV.Ex. ${ }^{a}$ el obsequio que pido para el bien de un menor, que todo lotiene pendiente en estaProvincia.

Esta ocasion me produce el gusto de tributar mis respetuosos homenages á V.Ex. ${ }^{a}$, á quien Dios Guarde muchos años.

Vice Consulado de España en la Ciudad de Rio Grande

á 21 del mesde Enero de 1847

Pablo de Goycoechea

Vice Consul

Anexo do Documento de 21 de janeiro de 1847

N. ${ }^{0} 1$.

Vice Consulado de España, en Rio Grande

Copia autentica

Ao III. ${ }^{\text {mo }}$ Sõr D. ${ }^{\mathrm{r}}$ Amaro José d'Avila da Silveira, Juiz Municipal d'Orffãos e ausentes da Cidade de Pelotas. 
O abaixo assignado Vice Consul de S.M. Cathólica en virtude de ordens do seu Governo teem á honra de levar ao conhecimento do Ill. ${ }^{\text {mo }}$ Sõr D. ${ }^{\mathrm{r}}$ Juiz Municipal d'Orffãos e ausentes da Cidade de Pelotas os documentos inclusos authenticados, que contem á reclamação que faz D. José Vizet filho ligitimo doHespanhol D. ${ }^{n}$ Antonio Vizet que falleceu habintestado no anrode 1844 na mesma Cidade.

$\mathrm{O}$ abaixo assignado pertende por tanto que no caso de se achar ainda no referido Juizo ó liquido producto da mencionada herança se lhe mande fazer entrega d'elle (deduzidas as despesas judiciaes) e dos livros e papeis arrecadados, uma vez que para isto se mostra plenamente authorizado pelos documentos inclusos que teem á honra de pôr debaixo das vistas de S. S. ${ }^{\mathrm{a}}$ formando á habilitação do reclamante.

$\mathrm{O}$ abaixo assignado saudando á S. S. ${ }^{\mathrm{a}}$ com o maior apreço e consideração, teem igualm. ${ }^{\mathrm{e}}$ á honra de assignarse.

De S. S. ${ }^{a}$ o mais affeiçoado

Pablo de Goycoechea

Vice Consul

Cidade do Rio Grande 14 de Dezembro 1846

Está conforme. Rio grande 21 deEnero de 1846

Pablo de Goycoechea

Anexo do Documento de 21 de janeiro de 1847

N. ${ }^{\circ} 2$.

Vice Consuladode España en Rio Grande

Copia Autentica

Legacion de España

en el Brasil

Acompaño a V. adjunta copia documentada delasolicitud que meha dirigido S. ${ }^{r}$ José Vizet hijo legitimo del español $D{ }^{n}$ Antonio Vizet que falleció abintestato en el año pasado1844 en Pelotas; á fin de quereclameV. dela autoridad competente el liquidode dicha herencia que sehalladepositado naturalmente en la Tesoreria y remitosu importe deducidos los gastos y derechos de oficio al Consul General de S. M. en Montevideo con los libros y demas papeles queserecojan y existan del difunto á fin de quese puedoliquidar en dicho ConsuladoGeneral la Testamentaria. Dios Guarda aV. Ex. ${ }^{a}$.

Rio de Janeiro 25 de Setiembre de 1846. José Delavat y Rincon. = Sõr Vice Consul de España en Rio Grandedel Sur. =

Está conforme con el original que queda en este Vice Consuladode España. Rio Grande 14 de Diziembre 1846 
N. ${ }^{0} 3$.

\section{Vice Consulado de España en Rio Grande \\ Copia autentica}

Sõr Ministro Presidente da S. M. Católica en Rio de Janeiro = D. José Vizet hijo legítimo y de legítimo matrimonio de D. ${ }^{\mathrm{n}}$ Antonio Vizet ya dífunto y deD. ${ }^{\mathrm{a}}$ Gracia Serra segun los documentos que en debida forma presento áVS. como suas haya lugar digo: Que mi citadoPadre D. ${ }^{\mathrm{n}}$ Antonio murió enla Provincia de Rio Grande en el año pasado 1844 , sin disposicion Testamentaría, de cuyas resultas el Juez de Intestados del Pueblo de Pelotas donde falleció, se hizo cargo detodos sus bienes alhajas, libros papeles y demas, ysegun he podido averigüar sehizo un remate detodolo exîstente depositando el dinero sin duva con arreglo á las Leyes de aquel Pais hasta tanto que acaseciese persona legitima en su reclamacion. En el momento se me notició la muerte de mi dicho difunto Padre, me embarqué en Barcelona con destino á esta Ciudad para hacerme cargo detodo lo perteneciente á él, con arreglo á lo establecido porlas Leyes Españolas de dondesoy natural, y en seguida dehaberme desembarcado me presenté en el Consulado Gral. de S. M. Católica residente en esta misma Ciudad á fin de quetubiese á bíen de ampararme como menor de edad y liquidarla testamentaria demi dicho difunto Padre con arreglo á lo prevenido en estos casos por existir enla mayor parte en esta la mayor parte de sus bienes. Segun llévodicho sehalla en el Pueblo de Pelotas, Provincia de Rio Grande una cantidad de dinero en déposito comoigualmente los libros y demas papeles todode pertenencia del citado mi Padre D. ${ }^{\mathrm{n}}$ Antonio Vizet, los que no ha querido entregar aquella autoridad á persona alguna. Los documentos que endevida forma he presentado en el Consulado General de S. M. Católica cerca de estaRepública, cuyas copias legalizadas adjunto á V.S. acreditan sin dejas duva alguna quesoy hijo legitimo del FinadoD. ${ }^{\mathrm{n}}$ Antonio Vizet y por consiguiente heredero forsoso de los bienes de aquel. Por esta razon para que á lamayor brevedad posible sepuedan arreglar segun corresponde las cuentas que dejó el finado, senecesitan los libros y demas documentos que existen en el Jusgado deIntestados de Pelotas, como tambien el dinero Depositado, y espero queVs. ${ }^{a}$ sesirva reciamarlos de quien corresponda por medio del Sõr Vice Consul del Rio Grande in otra persona queVS. ${ }^{a}$ tenga á bien comiscionar al afecto, ordenandole que cuanto se le entregue delapertenencia de Vizet lo ponga á disposicion del Consulado General enlaRepublica Oriental del Uruguay parololiquidacion dela testamentaria segun llevo referido con deducion delos gastos ocasionados. Porlo espuesto $=\mathrm{AVS}^{\mathrm{a}}$ suplico encarecidamente sedigna acceder á lo que llevo solicitado enel exordio de este escrito. Es gracia VS. $^{\mathrm{a}}=$ Montevideo 5 deSetiembre de $1846=$ José Vizet

Es copia

$$
=\text { Delavat } \mathrm{yRincon}=
$$

Está conforme, con el quesehalla en este Vice Consulado de España.

Rio Grande 14 de Diziembre 1846 
Anexo do Documento de 21 de janeiro de 1847.

N. ${ }^{\circ} 4$.

Vice Consulado de España, en Rio Grande

Cópia autentica

El infró Cura Parroco de la Parroquial Inglesia del Mar de Barcelona = Certifico y doy fé: que en uno de los Libros Parroquiales de Desposorios custodiados en el Archivo propio de mi Cargo, à saber, en el que comprehende los de 1828 , hasta los de 1835 , en el folio 7 " del mismo entre otros se halla continuada la partida del teuor siguiente. "Als diunit de Mars de mil vint cennts vint y unit, fetas la tres amoneztaciones, lo R. ${ }^{\mathrm{e}}$ Joseph Camps, Vic. Curat, assisti al Matrimoni celebrat per Anton Vizet, Perxer, fill de Joan y de Josepha Sastré conj. ${ }^{\mathrm{S}}=\mathrm{ab}$ Maria Gracia Serra, soltera, filla de Francisco y de Magina Juliá, conj., naturals dits contrahentes de Barña, y habitantes en la Parroquia. Testimonis Jacinto Bosch, y Manuel Vizet. $=\mathrm{D} .^{\mathrm{n}}$ Francisco Roques Vic. Perp. ${ }^{\text {" }}$ = I para que conste en la devida forma doy el presente testimonio en la Ciudad de Barña á los tres dias del mes de Junio del año mil achocientos cuarenta y seis firmado de mi mano ysignado con mi propio y acostumbrado $=\mathrm{Sig} \Psi$ no: José Gorgas $\mathrm{V}$. Perp. $^{\circ}=\mathrm{N}^{\circ}{ }^{\circ} 188=$ Art. 58 du Tarif $=$ Solvit six $\mathrm{f}^{\mathrm{eS}}=$ Un par nous, Ferdinand de Lesseps Consul de France à Barcelona, pour legalisation delasignature de dessus de D. ${ }^{n}$ José Gorgas desservant del' Eglise paroissale de Santa Maria del Mar en cetteVille = Barcelona, le 5 de Juin $1846=$ Le consul de France $=$ Ferd. de Lesseps. = Lugar del Se Fillo- =

E1 Consul general de la Republica de Chile en Cataluña é Islas Baleares $=$ Certifico: que el Cura Pàrroco dela Parroquial Iglesia de Santa Maria del Mar de Barcelona D. ${ }^{\mathrm{n}}$ José Gorgas, por quien vá firmada la que antecede estal como se titula y que à semejantes por èl libradas siempre se les ha dado y dá entera fé y crédito así en juicio como fuera de él, y para que conste lo firmo en Barcelona á 5 de Junio de1846. =

El Consul de Chille = I.M. Serra = Lugar del Se F 11 .

Esta conforme con el original que sehalla en este Consulado General de España. Montevidéo 4 de Setiembre $1846=$ Carlos Creus $=$ Lugar del Se T llo.

Esta conforme con los que quedan en este Vice Consulado de España. Rio Grande 14 de Diziembre 1846 -

Pablode Goycoechea 
N. ${ }^{0} 5$.

Vice Consuladode España, en Rio Grande

Copia autentica

El infrascrito Mayordomo dela Parroquial Iglesia de Santa Maria del Mar en la Ciudade de Barcelona = Certifico que en uno de les libros de bautismos dela mencionada Parroquia, entre otros selee una partida tal comosigue = "Als divnit de Dezembre de mil vintcents vint y vnit he batejat á Joseph, Francisco Anton, nat ahí fill de Anton Vitzet,

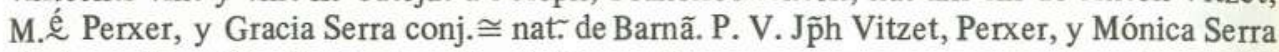
viuda $=$ Pere Mandó Pbrẽ y Curat "de vale" = y para que conste doy el presente testimonio, quesigno y firmo en Barnã á los tres dias de Junio demil ochocientos cuarenta yseis $=$ Sig $\Psi-1$ no $=$ Juan Perelló, Pbrõ $=\mathrm{N}^{\circ}{ }^{-}-190=$ art. $58 \mathrm{du}$ Tarif $=$ Solvit $=$ Six f es $=$ Un par nous, Ferdinand de Lesseps Consul deFrance à Barcelona, pour legalisation de la Signatur ci - desus de D. ${ }^{\mathrm{n}}$ Juan Perelló desservant de l'Eglise parvissiale de Santa Mariadel Mar en cette ville. $=$ Barcelona le 5 Juin 1846. $=$ Le Consul du France $=$ Ferdinand de Lesseps. $=$ Lugar del Sello = El Consul General dela República de Chile, en Catalunã á Islas Baleares $=$ Certifico que el Presbítero D. Juan Perelló, por quien vá firmada la que antecede es tal mayordomo dela Parroquial Iglesia de Santa Mariadel Mar comose titula, y que á semejantes por èl libradas sìempre seles ha dado y dá entera fé y crédito asi en Juicio como fuera de èl, y para que conste lo firmo en Barcelona á 5 de Junio de1846. = El Consul de Chile = I. M. Serra = Lugar del se F llo. = Esta conforme con el original quese halla en este Consulado General de España. Montevideo 4 de Setiembre 1846. = Carlos Creus = Lugar del Se

Está conforme con la copia que queda en este Vice Consuladode España. Rio Grande 14 de Diziembre de 1846.

Pablode Goycoechea

Anexo do Documento de 21 de Janeiro de 1847

N. ${ }^{\circ} 6$.

Vice Consulado de España en Rio Grande

Capia autentica

El infrascrito Mayordomo dela Parroquial Iglesia de Santa Maria del Mar en la Ciudad de Barcelona = Certifico: que en uno de los libros de bautismos de la mencionada Parróquia, entre otras selee una partida del teuor siguiente: = "Als vint yset de Juli ol de mil vintcents cinch per mi infraescrit fou batejat Joseph, Anton, Juaquin, fill legitim y 
natural de Pere Joan Vizet, Perxer y de Josepha Sastre conj. nats̃ de Barcelona. P. V. Celdoni Sastre Mestre de axa y Gertrudis Sastre, donsella = Francisco Guals Pbre Curat". $\mathrm{Y}$ para que conste, doy el presente Testimonio que signo y firmo em Barcelona á los cuatro de Junio de mil achocientos cuarenta y seis $=\mathrm{Sig} \mp$ no $=$ Juan Perelló Pbro. $=$ N. ${ }^{\circ} 189$ Art. $^{\circ} 58$,du Tarif. $=$ Solvit $=$ Six f. ${ }^{\text {es }}=$ un par nous, Ferdinand de Lesseps, Consul de France á Barcelona, pour legalisation de la Signature ci-dessus de D. Juan Perelló desservant del' Eglise Parroisale de Santa Maria del Mar en cette ville $=$ Barcelona de 5 Juin 1846. $=$ Le Consul de France $=$ Ferdinand de Lesseps $=$ Lugar del Se F $110=$ El Consul General de la Republica de Chile en Cataluña e Islas Baleares $=$ Certifico: queel Presbitero D. Juan Perelló, por quien va firmada la queantecede es tal Mayordomo de la Parroquial Iglesia de Santa Maria comosetitula y que asemejantes por el libradas, siempre seter ha dado y dá entera fé y crédito asien Juicio como fuerade él: y para que conste lo firmo en Barcelona á 5 de Junio de 1846. = El Consul de Chile $=\mathrm{J} . \mathrm{M}$. Serra $=$ Lugar del Se Fillo. = Está conforme con el original quesehalla en este ConsuladoGeneral de España. Montevideo 4 de Setiembre de1846 $=$ Carlos Creus $=$ Lugar del Se T 1 lo. $=$

Esta conforme conel que queda en este Vice Consulado deEspaña. Rio Grande 14 de Diziembre 1846

Pablo de Goycoechea

Anexo de Documento de 21 de janeiro de 1847

N. ${ }^{0} 7$

Vice Consulado de España en Rio Grande Copia autentica

Receby do Sr. Domingos Rodrigues Cordeiro hum officio con vários Documentos nelle mencionados, do Sõr D. Pablode Goycoechea, concernentes a

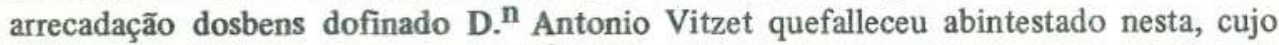
officio e exigencia solicita na qualid. ${ }^{\mathrm{e}}$ de Vice Consule da Nação Hespanhola na Cidadede Rio Grande.

Pelotas 15 de Desembro de1846

$$
=\text { José Vieira Viana }=
$$

Suplente do Juizo Municipal

Está conforme con el original que queda en este Vice Consuladode España. Rio Grande 21 de Enero de 1847. 
Al Ill. ${ }^{\mathrm{mo}}$ y Ex. ${ }^{\mathrm{mo}}$ Sõr Presidente de la Prov. ${ }^{\mathrm{a}}$ de R. ${ }^{\circ}$ Grande

del Sur. Dón Manuel Antonio Galvão

El infrascrito Vice Consul de S. M. Católica, al dirigirse à V. Ex. ${ }^{a}$, tiene la honra de poner ensuconocimiento de que en cumplimiento de las ordenes de este Vice Consulado y en observancia de lo dictado por S. Ex. ${ }^{\mathrm{a}}$ el Sõr Vice Presidente, para à esa Ciudad, el subdito Espanõl D. Francisco Gutierres. Este individuo establecido y con negocios mercantiles algunos anõs há enla Villade Bagé, laborioso y honrado notoriamente; sufrió una prision de $51 / 2$ meses suponiendolo promotor de deserciones en el Egercito Imperial y como complice suyo, tambien al espanõl D. Rafael Sabáran, igualmente pácifico y con negocios comerciales en dichaVilla, apuntandolos como Orientales!

Porlas notas pasadas entre la Legacion de España y S. Ex. ${ }^{a}$ el Sõr Ministro de Relaciones Extrangeras en Rio de Janeiro, sehabia recomendado al Sõr Vice Presidente de que antes de poner en egecucion la disposicion anterior, que era la de que fuesen espulsos del Pais, tomase nuevos informes respecto las denuncias hechas contra dichos individuos ysi fuesen menos fundadas seles permitiese continuar à residir en la Provincia. El Sõr Vice Presid. te les marcó el plazo de 2 meses; plazo Ex.mo Sõr, que no corresponde à redondear, ni menos à transigir parte desus intereses, porque generalmente las transacciones enla campaña son permutadas; y los productos del Pais, se entregan, segun permitan la estacion y circunstancias.

Los documentos comprobantes quesehallan en este Vice Consulado, de personas de respetabilidad avecindados ytambien negociantes; acreditan la buena conducta observada por Gutierres, confirmando aun otro deigual mérito, del Coronel, Diputado Aj. ${ }^{e}$ Gen.al Dón Cásimiro José da Camara ySá cuyo original remití hacen 2 meses, à la Legacion, al Rio de Janeiro. En este concepto Ex. ${ }^{\text {mo }}$ Sõr, no es facil de equivocarse paradecir; de que las acusaciones de los delatores de Gutierres y Sobáran eran indeterminadas y pococoncluyentes y en que se descubrela debilidad desu fondo. Por que, i que interés podían tener los mencionados Gutierres ySobáran, ya no digo en seducir tropa, sino mismo, en alternar con soldados, que no están colocados ensu esfera ? i Rebajarse, hombres relacionados de un modo regular enla Sociedad, para perder su crédito? Cuesta à creerlo.

Ex. ${ }^{\text {mo }}$ Sõr, Francisco Gutierres, para lavarse dela mancha con que han querido implicarle, en desprecio delaverdad, deseaservido en juicio, pues no reclama sinó justicia $\mathrm{y}$ el infascrito no pudeindo negarla à la pretencion de un subdito de $\mathrm{S}$. M. Católica, ni dejarde prestar la proteccion legal à sus derechos postergados y à sus propiedades abandonadas, se promete dela rectitud $\mathrm{deV}$. Ex. ${ }^{\mathrm{a}}$, dejará espeditos para el referido individuo los medios desu vindicacion ante las Justicias del Pais; cuya accion el infrascrito, nodesea ni remotamente, sea trabado en el jurgamiento del caso à queserefiere Francisco Gutierres.

Tengo la honra desaludar à V. Ex. ${ }^{\mathrm{a}}$ con toda consideracion y aprecio.

Dio Guarde à V. Ex. ${ }^{a}$ muchos años.

Vice consuladode España en la Ciudad de Rio Grande à 28 de Enerode 1847.

Pablo de Goycoechea

Vice Consul 
'Al Il ${ }^{\mathrm{mo}}$ y Ex ${ }^{\mathrm{mo}}$ Sir Presidente dela Província de Rio Grandedo Sul, Dón Manuel Antonio Galvão.

Para cumplir los deberes que me están incumbidos me tomo la libertad de dirigirme á V.Exa ${ }^{a}$; para que por intermedio dela Autoridade competente se hagan las necessárias Diligencias, para que sea puesta enlibertad y restituida á sus Padres, la niña por nombre, Andrea Hernandez hija legitima del Espanhol Domingo deLa Luz Hernandez; cuya niña fué llevadadesu compañia porD ${ }^{\mathrm{a}}$ Asención Aries para Porto Alegre;y quesehalla enpoder dedicha señora.

Los documentos que acompaño servirán para corroborar, lajusticia y la legitimidad delareclamacion del infeliz Domingo dela Luz Hernandez; agregando que, en Agosto del año pp. ${ }^{\circ}$, permaneciá dicha niña, en compania dela mencionada D. ${ }^{\mathrm{a}}$ Asuncion Aires, en una chacra, suburbios de esa Ciudad de Porto Alegre, lugardesu residencia.

Solicitando la poderosa y eficáz intervencion de V. $\mathrm{Ex}^{\mathrm{a}}$ para alcansar los fines, paralos cuales, tengo ahora lahonrade dirigirme; tambien aprovecho la ocasion de mi perfecta consideracion y respeto.

Dios guarde á V.Ex ${ }^{\mathrm{a}}$, muchos años. Vice consulado deEspaña en Rio Grande, á 22 de Marzo de 1847.

Pablo de Goycoechea.

\section{ANEXO 1}

Habiendo hecho presente á los Padres dela niña Andrea Hernandez de las investigaciones del Señor Vice Consul de S.M. en Rio Grande,y la necessidad por consiguiente de presentar los documentos que acreditasenla legitimidad en que funda su incuestionable derecho de reclamacion, exhibio ante esta Legacion y Consulado General el que, tengo el honor de remitir à V.S. adjunto, que sirvió para hacer en otra ocasion diligenciar semejantes, quenotuvieron efecto á pesar dela substitucion de los poderdantes Dón Salvador Basseda y Dón José Martorell.

Este documento aunque expedido el año pp. ${ }^{\circ}$ llena el objeto que en aquella fecha y en la presente se propusieron los recurrentes, que es el deprobar la legitimidad de Padres, de la niña en cuestion, ysu transporte clandestino á Porto Alegre por $\mathrm{D}^{\mathrm{a}}$ Asencion Aries: cuyo documento legalizado en debida forma por este consulado General, poneal Sõr Vice Consul de S.M. en Rio Grande en disposicion de entablar dicha reclamacion ó nombrar alguna persona desu confianza quelo verifique.

Los Padres de esta niña, humildes trabajadores, me han significado justamente: que todavez quela señora Areas llevó asu hija clandestinamente en su compañia sin conocimiento y consentimiento de ellos, es justo que aquella señora satisfaga los gastos de viage, y otros, quese originen al transladarla al seno de su familia; reclamando igualmente el producto que pueda pertencerle dela chancelacion de cuentas correspondientes á sus salarios mensuales, á que és acreedora la niña Andrea Hernandez, 
que en clase de criada recibió en sua casa la referida Doña Asencion Aries=La triste situacion de estos padres infelizes me hace recomendar á V.S. muy particularmente esta asunto, para que sirviendose hacerlo al Vice Consul de S.M. en Rio Grande, se pueda obtener un resultado satisfactorio.

$$
\begin{gathered}
=\text { Es Copia }= \\
=\text { Delavat y Ricon }=
\end{gathered}
$$

Está conforme con el Documento visado por S.Ex ${ }^{\mathrm{a}}$, el Sõr Ministro de S.M. Catolica en Rio deJaneiro, que queda en este Vice Consulado deEspaña. Rio Grande á 22 del mes de Marzode1847.

Pablo de Goycoechea.

ANEXO 2

Vice Consulado de España en Rio Grande Copia Autentica

Solicitud Señor Gefe Politico y de Policia = Domingo de la Luz Hernandez, soldado dela $2 .^{\circ}$ Legion de Guardias Nacionales, á V.S. con todo respeto vice: Que habiendole enbarcado clandestinamente $\mathrm{D}_{\stackrel{\mathrm{a}}{\mathrm{a}} \text { Asencion }}$ Aries, una hija legitima, y trasportadola á Porto Alegre, y para poderlareclamar sevè precisado á implorar larecta justicia de V.S. para quepor el Departamento desu cargo, sereclame del Gobierno de aquellaProvincia, bajo la correspondiente legalizacion, del Consul de S.M. Imperial en esta; y á V.S. suplica, se sirva admitir la informacion Informacion que presenta, al teuor delas preguntas siguientes $=$ Primera $=\mathrm{Si}$ saben $\mathrm{y}$ les consta de publica voz, y fama, quesoy Domingodela Luz Hernandez, y que está hasido transportada clandestinamente á Porto Alegre, en Rio Grande por $\mathrm{D} \underline{\underline{\mathrm{a}}}$ Asencion Areas $=$ Segunda $=$ Igualmente si saben quesoy soldado (segun me he espresado) del $4 .^{\circ}$ Batallon dela $2 .^{\circ}$ Legion de Guardias Nacionales, pobre, é imposibilitado por faltade medios para practicar estas diligencias juiciales con el poder bastante; $y$ en su virtud estando conforme, se sirvaV.S. ordenar, se pase la correspondiente nota al Sir. Consul, ó al Encargo de negocios del Brasil, si a otro que pertenesca, para que allane al fuero que corresponde; dignandose quesean estar autorisadas por el Escribano Publico D. ${ }^{\mathrm{r}}$ Juan Paunero, el quedará el competente testimonio, signado por V.S. y autorisado en forma; que es justicia que imploro, juro no proceder de malicia y para ello. $=$ A ruego de Domingodela Luz Hernandez, por

Decreto nosaberseescribir firmo Felipe Gonzales=Departamento de Policia, Montevideo Marzo trez de mil ochocientos cuarentay cinco = Comosolicita; con la comision bastante, quesele confiere al Actuario: 
Notificac. $^{\mathrm{n}}$

Declaracion de Antonio Benito Marichal

Declaracion de Pascual Sore. de Medina

Declaracion de Lorenzo Padilla
Asi lo decretó el Sõr $\mathrm{D}^{\mathrm{n}}$ Juan Francisco Rodriguez, Gefe Politicoy de Policia de este Departamento, por ante mi de que doy fé = Juan FranciscoRodriguez $=$ Antemi Juan Paunero escribano público $=\mathrm{El}$ dicho dia, mez y año, notifiqué á Domingo dela Luz Hernandez el ántecedente decreto, en su persona de que doy fé, no firmó por nosaber, lo hizo á su ruego, D. ${ }^{\mathrm{n}}$ Felipe Gonzalez $=$ Pauncro $=$ En la referida ciudad reconquistadora de S. ${ }^{n}$ Felipe y Santiago de Montevideo á presentacion de Domingo de la Luz Hernandez compareció D. Antonio Benito Marichal, vecinode esta en virtud del antecedente decreto, yo escribano tomé y recibí juramento que hizo por Dios Nuestro Señor, y unaseñal de cruz, bajo del cual prometió decir verdad, cuanto supiere y fuere preguntado, y siendolo al teuor de las preguntas dela antecedente solicitud dijo: Primera si sabe y le consta de pública voz y fama, queDomingo de la Luz Hernandez, es padre legitimo de Andrea Hernandez, y que estahasido transportada clandestinamente á Porto Alegre por $\mathrm{D} \underline{\underline{\mathrm{a}}}$ Asencion Aries = Dijo quesi que es certa en todassus partes estapregunta $=$ Segunda $=$ si sabe y le consta que el esprezado Hernandez, es soldado del $4 .^{\circ}$ Batallon de la $2 .{ }^{\circ}$ Legion de Guardias Nacionales, y quesu estado de pobreza, leimposibilita enteramente paraseguir judicialmente estas Diligencias $=$ Dijo; que es cierto el contenidode esta pregunta: Que es cuantosabe, y puede decir atento á lo queseleha preguntado, y laverdad bajo del juramento queha prestado, en quese afirma yratifica; leida quele fué esta declaracion, dijo ser de edad de cincuenta y un años, nofirmó por nosaber rogó á $\mathrm{D}^{\mathrm{n}}$ Cayetano Bover lohiciese á su nombre que de todo, yo Escribano doy fé $=$ Cayetano Bover $=$ antemi Juan Paunero $=$ En la misma ciudad, acto continuo de la misma pretencion digo de la misma presentacion y en el mismodia delafecha, compareció D. Pascual José de Medina de esta vecindad, á quien yo Escribano, tomé y recibi juramento que hizo en forma, bajo del cual, ofreció decir verdade; y preguntad pregunta por pregunta, y palabra por palabra en las que contiene la antecedente declaracion, conforme á la presentacion quevá por Cabeza, contestó son todas ciertas y verdaderas, las que leidas, seratificó en ellas, en estasu declaracion, siendode edad de setenta ysiete años; no firmó porque dijo nosaber, rogó igualmente al anterior testigo lo hiciera por él; firmó y firmé de que doy fé $=$ Cayetano Bover $=$ Antemi Juan Paunero $=$ En la referida ciudad, dia, mes, y año; y dela misma conformidad, compareció D. ${ }^{\mathrm{n}}$ Lorenzo Padilla de estavencidad, al que tomé y recibí juramento en forma, y siendo preguntado enla mismaforma que antecede enlas declaraciones recibidas, dijo ser conforme á laverdad, y de público y notorio, enlas quese ratifica, en todas sus partes; no firmó por nosaber, ruega al referido Testigo D. ${ }^{\mathrm{n}}$ Cayetano Bover lo haga en su nombre, siendo de edad de treinta y nueve años poco mas ó menos, firmó y firmé de que yo Escribano doy fé $=$ Cayetano Bover $=$ Antemi Juan 
Paunero $=$ Departamento de policia, Montevideo cuatro de Marzo de mil ochocientos cuarenta y cinco: Acto contínuo compareció ante mi el el Sõr Gefe Politico yde Policia D. ${ }^{n}$ Juan Francisco Rodriguez, y por ante mi Escribano, Domingodela Luz Hernandez, vecino de esta, á quien doy fé que conosco y dijo: Que estando conforme su solicitud, segun seleha hecho saber para poder hacer el reclamo desú hija legitima;

Sei y confiere, todo su poder especial, para que comparesca ante las Autoridades competentes del Rio Grande, ademas puntos del Estado Brasileiro, a $\mathrm{D}=$ nalvador Basseda, y á $\mathrm{D} \cong$ J José Martorell, vecinos de Sán Francisco de Pelotas, y en su nombre representando sus derechos, y acciones hagasolicitudes, presente escritos, y todo cuanto hacerpudiera, presente el otorgante, pues para todo les dá el mas amplio poder, con clausula espresa de q. ${ }^{e}$ le puedan substituir en quien y como mejor les pareciere, revocarsubstitutor, y crear de nuevo, con libre, franca y general administracion y relevacion en forma; que al efecto obliga su persona y bienes habidos y por haber, dandopoder, á las justicias, y juerer competentes paraque selohagan guardar, y egecutar; renunciando todas las leyes, fueros, y derechos, desu favor, y la general en su favor digo en forma. Y por firme; asi lo dijo y otorgo, siendotestigos, D. ${ }^{\mathrm{r}}$ CayetanoBover, y D. ${ }^{\mathrm{n}}$ Felipe Consales, ambos vecinos de esta; no firmó por nosaber, y lohizo asuruego el mencionado Bover, de queyo Escribanodoy fé $=$ Cayetano Bover $=$ Por mandato de su señoria, Juan Paunero $=$ V $\cdot$ B. ${ }^{\circ}=$ Juan Francisco Rodriguez .

Es copia del original que queda archivado enla oficina del Departamento de Policia, de esta Capital, á que me permito y paralos fines que hayalugar de orden de su Señoria, losigno y firmo enla Ciudad de San Felipe y Santiago de Montevideo á veinte y cuatro dias del mes de Marzo año demil ochocentos cuarentay cinco de que doy fé $=$ Enmendado cuatro $=$ Vale Lugar del signo $\vec{F}=$ Por $\mathrm{m}$. do de S.S. $=$ Juan Paunero, Escr. ${ }^{\circ}$ Publico $=$ V.${ }^{\circ}$ B. ${ }^{\circ}=$ Juan Fran. ${ }^{\text {co }}$ Rodriguez $=$ Manoel Vieira Braga.

Consul General do Imperio do Brazil em Montevideo $=$ Reconheço verdadeiras as assignaturas supra de D. Juan Francisco Rodriguez, chefe de Policia nesta Capital, e deJuan Paunero, Escrivão Publico na mesma; e para constar onde convier, á pedido daparte interesada, mandei passar á presente que assignei, e fiz sellar com o sello das Imperiaes Armas deste Consulado Geral doBrasil em Montevideo aos 26 de Março de $1845=$ Manoel Vieira Braga $=$ Lugar del Se 王llo $=$ Gratis $=$ N $.0_{1}$ $\mathrm{R}^{\text {S }} 480=$ P.g. quatrocentos e oitenta reis Pelotas 14 de Maio de $1845=$ Godinho $=\mathrm{S} . \mathrm{z}=$ substabeleço ospoderes constantes desta Procuração na pessoa do Sõr Antonio José Sovre Pinto, ficandomeos mesmos en inteiro vigor $=$ Pelotas 14 de Maio de $1845=$ SalbadorBasedo $=$ José Martorell $=\mathrm{D} .{ }^{\mathrm{n}}$ Carlos Creus, caballero supernumerano dela Real y distinguida ordem de Carlos Tercero, comendador dela Real Orden de Cristo deProtugal, Encargadode Negocios en la Republica Oriental del 
Uruguai residente en este Puerto de Montevideo = Certifico: que D. Juan Paunero por quien sehallan autorizadas las diligencias obradas en averiguacion delalegitimidad de una hija de Domingode la Luz Hernandez que D. ${ }^{\mathrm{n}}$ Asencion Aries lallevó á Porto Alegre furtivamente, és comose titula Escribano Público, y á cuantos actos practica como tal, se les dá entera fé y crédito así en juicio como fuerade él, siendo asi mismo cierto que por esta Legacion seha reclamado antes de ahora lareferida niña cuyas diligencias las está practicando el el Vice Consul Español del Rio Grande actual encargado para recogerla y mandarla á esta ciudad. Y para que conste y puedan tener cumplido efecto las reclamaciones del Vice-Consul de S.M. en Rio Grande relativas á la entregade la niña Andrea Hernandaz, por D. ${ }^{\text {na }}$ Asencion Aries, espidola presente con el Real Sello de este Consulado en Montevideo á veintitres de Octubre de mil ochocentos cuarenta yseis $=$ Carlos Creus $=$ Lugar del se '

Está conforme con los Documentos Sellados y rubricados que sehallan en este Vice Consulado de España.

Rio Grande á 22 del mes de Marzo de 1847

Pablo de Goycoechea

\begin{abstract}
Al. Ill. ${ }^{\mathrm{mo}}$ y Ex. ${ }^{\mathrm{mo}}$ Sõr Presidente dela Provincia
deRio Grande del Sur, Dón Manuel Antonio Galvão
\end{abstract}

Tengo el gusto de acusar el recibo del ofício deV. Ex. ${ }^{\mathrm{a}}$ datado el 30 de Marzo pp. ${ }^{\circ}$, de cuya fina atencion, vindo á V. Ex. ${ }^{\mathrm{a}}$, las correspondientes gracias.

A respecto dela niña Andrea Hernandes, que sehalla en poder deD. Asencion Aries, objeto dela reclamacion, paraser restituida à sus Padres; con estadata autorizo à Dón José Ramán Maciel, negociante establecido en esa Ciudad, y con familia; para que, larecoja à su poder, envirtud delaresolucion deV. Ex. ${ }^{\mathrm{a}}$; y obre en conformidad de mis instrucciones, remitiendome dicha ninã en companĩadefamilia; à fin de proceder del mismo modo su envío desde esta Pto, al Sõr. Encargado de S. M. Catolica, en Montevideo.

Tengolasatisfaccion dereiterar à $\mathrm{V}$. Ex. ${ }^{\mathrm{a}}$ mi firme consideracion y respeto.

Dios Guarde à V. Ex. ${ }^{a}$ muchos anõs. Vice Consulado deEspanã en Rio Grande à 8 de Abril de 1847 . 
Al Illmo y Ex ${ }^{\text {mo }}$ Sõr Presid ${ }^{\text {te }}$ y General del Exercito dela Prov. del Rio Grande del Sur, Don Franco José de Sousa Soares de Andrea

Tiendo recibido El oficio deV. Ex. ${ }^{a}$ para el Sõr comand ${ }^{\mathrm{e}}$ deBagé que, mañana seguira $\mathrm{p}^{\mathrm{a}}$ dicha Rt.

Agradezco altamente lafina atencion que $\mathrm{V} \mathrm{Ex}{ }^{\mathrm{a}}$ me hadado porla reclamacion hecha porlos subditos demis Augusta Soberana, La Sra D. ${ }^{\mathrm{a}}$ Isabel $2^{\mathrm{a}}$, residentes y con negocios comerciales endicha viladeBagé y a quienes los considero pácificos y laboriosos.

Aprovecho nueva ocasún dereiterar à V. Ex ${ }^{\mathrm{a}}$ la expresun demi perfecta consideracy $^{\mathrm{n}}$ respeto.

Vice Consulado deEspaña en Rio Gre 29 de Abril de 1848

\author{
Pablo de Goycoechea \\ V. consul
}

Al Ill ${ }^{\mathrm{mo}}$ y Ex ${ }^{\mathrm{mo}}$ Sõr Presid. ${ }^{\mathrm{e}}$ General del Exercito, de Rio $\mathrm{Gr}^{\mathrm{e}}$ Don Fran. ${ }^{\text {co José de }}$ Sousa Soares de Andrea

$\mathrm{El}$ abajo firmado al dirigirse en la ocasion à $\mathrm{V}$. Ex ${ }^{\mathrm{a}}$ tiene por objeto poner en su conocimiento losiguiente.

Los Españoles Juan Zoveran y Fran ${ }^{\text {co }}$ Ragull, segun declaracion este, dueño y Patron del Lanchon señalado con el n. ${ }^{\circ} 82$ y aquel en la misma clase, con el n. ${ }^{\circ} 85$, han sido compreendidos en los articulos 6, 60 y 76 del Reglamento de Puerto y para su cumplimiento, el ilustre Sõr $\mathrm{Cap}^{\mathrm{n}}$ de Puerto de estaProv. ${ }^{\mathrm{a}}$ les impuso prision y multa competente. Yo conosco Ex ${ }^{\mathrm{mo}}$ Sõr de que dichos individuos fueron infractores y merecian correccion y sufrieron, pero tambien a mi pedido el caballero Sõr Ferras los alivio dias de prision, por cuya atencion soy agradecido. Entretanto concurre la circunstancia de que está pediente la entregade los mencionados lanchones a suspropietarios hasta laresolucion de V. Ex ${ }^{\mathrm{a}}$; y por lo mismo me permitirá V. Ex ${ }^{\mathrm{a}}$ le haga una observacion bien persuadido de que sedignara admitir en su consideracion; y hará justicia comtienede costumbre enfavor de los referidos españoles.

Ellos han navegado es cierto, los rios interiores del Pais, pero han navegado de un modo simple y pácifico ignorando las Leyes del Imperio a tal respecto: laboriosos procuravam asiduamente sus adelantes y adquirieron con sus desvelos sus barquitos y ahora estrañan su privacion.

Perdone V. Ex ${ }^{\mathrm{a}}$ el que haya molestado su atencion y tengolasatisfaccion dereitarar a V. Ex ${ }^{\mathrm{a}}$, mi aprecio y respeto

Dios guarde a V Ex ${ }^{\mathrm{a}}$ muchos años. Rio Grande à 21 de julio de 1848

Pablo de Goycoechea

V. consul 
Me es complaciente acusar el recibo del oficio $\mathrm{deV} \mathrm{Ex}^{\mathrm{a}}$ de 11 del cons mes relativam ${ }^{\mathrm{e}}$ á los Lánchones detenidos en esta capitaniade Puerto, depropriedad delos españoles, Juan Zoveran y Fran. ${ }^{\mathrm{CO}}$ Ragull; y de queenvirtud dela orden expedidapor V. $\mathrm{Ex}^{\mathrm{a}}$, este sõr Cap ${ }^{\mathrm{n}}$ dePuerto entregó los referidos lanchones.

Por tal motivo llevo eldeber detributar á V. Ex ${ }^{\mathrm{a}}$ las mas expresivas gracias.

Saludo a V. Ex ${ }^{\mathrm{a}}$, contodo aprecio, á quien Dios Guarde muchos años. Vice consulado de España en Rio Grande a 22de Agosto de 1848

Ill $^{\text {mo }}$ y Ex ${ }^{\text {mo }}$ Sõr Presidente y General dela Prov ${ }^{a}$ delRio $G^{\text {de }}$ do Sul Don Fran ${ }^{\mathrm{co}}$ de Sousa Soares de Andrea.

Pablo de Goycoechea

V. consul de S. M. Catolica

$$
\text { Ill.o e Exm. o Snr? }
$$

Representa a este Vice Consulado de S.M.Catholica o subdito Hespanhol Manoel d'Andrade, d'havendo sido indevida, e illegalmente recrutado pa o Serviço d'Armada Imperial, se acha com praça assente, e forçado a Servir a bordo da Canhoneira de Guerra S. Lepoldo, ao pres. e surta no porto desta Cidade, e não podendo suscitar-se duvida algua a cerca de sua nacionalidad. e como mostra o docum. to d'incluso tenho a honra de levar as mãos de V. Ex. ${ }^{\mathrm{a}}$ e sendo incontestavel d.'a sua dualidad. de estrangeiro o garante de todo e qualquer serviço forçado por isso o abaixo assign.do roga á V. Ex.a se digne expedir com a brevidade possivel as convenientes ordens para d.' o referido subdito seja posto em plena liberdade e na precição de seus direitos. Aproveitando esta ippunidade o abaixo assignado tem a subida honra de significar a V.Ex. a os sentim.tos de maior respeito e alta consideração. Deus G.de V. Exa. m.tos an. $\mathrm{S}$

Vice Consulado de S.M.C. em Porto Alegre 2 de outubro 1851. Illm. ${ }^{\circ}$ Exm. ${ }^{\circ}$ Snr. Patricio Corr. ${ }^{a}$ da Camara Digm. ${ }^{\circ}$ Vice Prez. ${ }^{e}$ desta Prov. ${ }^{a}$

João Pereira Machado

Vice Consul 


\begin{tabular}{|c|c|c|c|c|c|c|c|c|c|c|c|c|c|c|c|}
\hline \multicolumn{5}{|c|}{$\begin{array}{l}\text { CAPITANIA DO PORTO DA } \\
\text { MATRICULA DA }\end{array}$} & $\begin{array}{l}\text { E } \\
\text { POR }\end{array}$ & Tul & UI & \multicolumn{8}{|c|}{$\begin{array}{l}\text { PROVINCIA DE S. PEDRO } \\
\text { GENTE DO MAR }\end{array}$} \\
\hline Nomes & \multirow{4}{*}{$\begin{array}{l} \\
\mathscr{2} \\
\text { 岕 }\end{array}$} & \multirow{4}{*}{ 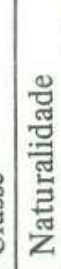 } & \multirow{4}{*}{ 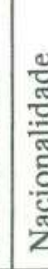 } & \multirow{4}{*}{ ن } & \multirow{4}{*}{ 茪 } & \multirow{4}{*}{ 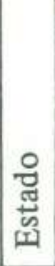 } & \multirow{4}{*}{$\begin{array}{l}\text { 。 } \\
\text { ల్ల } \\
\text { ల్ }\end{array}$} & \multirow{4}{*}{ 总 } & \multirow{4}{*}{ 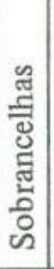 } & \multirow{4}{*}{ 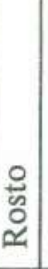 } & & \multirow{4}{*}{ 思 } & \multirow{4}{*}{ 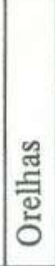 } & \multirow{4}{*}{ 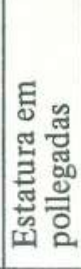 } & \multirow{4}{*}{ 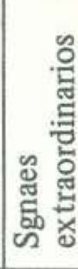 } \\
\hline Manoel d'Andrade & & & & & & & & & & & \multirow{3}{*}{ 금 } & & & & \\
\hline Filiação & & & & & & & & & & & & & & & \\
\hline Pian d'Andrade & & & & & & & & & & & & & & & \\
\hline & $\begin{array}{l}0 \\
\text { L } \\
2\end{array}$ & 蔦 & $\begin{array}{l}\overline{0} . \\
\text {. } \\
\text { i }\end{array}$ & 蛋 & 究 & 올 & 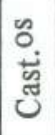 & 总 & $\begin{array}{l}\text { ô. } \\
\text { s. } \\
\text { J }\end{array}$ & 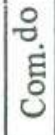 & 它 & 瓷 & $\begin{array}{l}\mathscr{\Theta} \\
\dot{d} \\
\mathscr{\alpha}\end{array}$ & in & \\
\hline
\end{tabular}

Em observancia ao capitulo $2 .^{\circ}$ Titulo $4 .^{\circ}$ do Regulamento de 19 de maio de 1846 a cujas desposições fica sujeito o individuo supra.

Rio Grande do Sul 30 de abril de 1850

O Capitão do Porto

Antonio Caetano Ferrazi

Visto em 19 de Maio 1850

(Medeiros)

Visto em 7 de julho de 1850

(Medeiros)

Visto na Capitazia d'(Jag.m)

em 7 d'Ag.to d'1850

Interinam.te

(J.0 Theodosio Glz)

Visto em 6 de Julho de 1851

Luzitano

(a seguir no Verso do Documento)

Visto em 18 de Dez. ${ }^{\circ}$ de 1850

[ass.ilegivel]
Visto em 2 de Fevereiro de 1851

[ass. ilegivel ]

Visto em 2 de Março de 1851

[ass. ilegivel]

[ass. ilegivel ]

Visto em 3 de Agosto 1851

[ass.ilegivel]

O Secretario

[ilegível]

Visto em 1.0 de

Setembro de 1850

A.C. Ferraz Cap. $m$ do Porto

Visto em 12-5-51

[ass.ilegivel]

[Seguem várias assinaturas]

Visto em 8 de Jan.ro de 1851

[ass.ilegivel] 
O abaixo assignado Vice Consul de S.M. Catholica nésta Cidade, em officio de 2 do Corr. te solicitou da Presidencia da Província as convinientes ordens para que fosse posto em liberdade o Subdito Hespanhol Manoel Andrade, que representava a este Vice Consulado acharse com praça assente e forçado a servir a bordo da Canhoneira S. Leopoldo surta neste porto. S. Ex.cia e Snr.' Vice Presidente teve abondade de responder em officio de 4 dom. mo mes que não podia mandar pôr em liberdade aquelle subdito sem que o abaixo assignado exigisse delle e remetese a Presidencia sua Papelita ou Habilitação, visto que a matricula que apresentava não era documento suficiente para provar sua Nacionalidade.

Avista do que o abaixo assignado tem a honra de levar as mãos de V. Ex.a aquella Papelita ou Habilitação exigida, e de novo rogar a V. Ex. ${ }^{a}$ haja de dar as convinientes ordens para que seja posto em liberdade aquelle subdito. Outrossim faz vêr a V. Ex..$^{a}$ que aquella Canhoneira está a seguir viage deste Porto no dia 27 do Corr., e assim rogo a V. Ex.cia seja a ordem de soltura dada a tempo que possa aproveitar ao m. mo subdito antes da partida daquelle vazo de Guerra.

$\mathrm{O}$ abaixo assignado de novo tem a subida honra de significar a V. Ex.cia os sentimentos do seu maior respeito e alta consideração.

Dios Guarde a V. Ex. ${ }^{\mathrm{a}}$ muitos annos.

Vice Consulado de S.M.Catholica em Porto Alegre 25 de outubro de 1851

Ill.mo é Ex.mo Snr? D.or

Luis Alves Leite de Oliveira Bello

D. Vice Presidente desta Prov.cia

João Per. ${ }^{a}$ Machado

Vice Consul

Ill.mo e Ex.mo Snr?

Tornando-se me de absoluta precizão sahir temporariamente d'esta Capital para percorrer a bem de meus negocios alguns pontos da Provincia, e não convindo, que durante minha auzencia fiquem em abandono os interesses de S.M.Catholica, e de Seus subditos, fica encarregado da gerencia deste Vice Consulado e para fazer minhas vezes no meu impedimento o Chanceller de S.M.Fedilissima Antonio Maria do Amaral Ribeiro, e porisso a bem do serviço de Sua dita Magestade, rogo a V. Ex.cia se digne attender as reclamações, que por acazo elle tenha de fazer.

Deos Guarde a V. Ex.cia muitos annos.

Vice Consulado de S.M.Catholica em Porto Alegre 30 de Outubro de $1851=$ Illm. ${ }^{\circ}$ e Ex.mo Snr? D. or Luiz Alves Leite de Oliveira Béllo

D. Vice Presid.e da Prov.cia 


\section{$\mathrm{Ex}^{\mathrm{mo}}$ Sor.}

El subdito de S.M.Católica, Fernando Ortiz, vecino y del comercio dela Ciudad de Pelotas, fué violentamente arrebatado de sucasa, por orden del Ill. ${ }^{\text {mo }}$ Sõr. Delegado de Policia, con su Esposa, un dependiente y una esclava suya y llevados todos á la Carcel Publica dedicha, Ciudad, en medio del dia, y á lafàz detodo el Mundo con vejamen de su reputacion y con perjuício ìrreparable de susintereses, los quales no parecen garantidos por dicha Autoridad y que fueron ambos así, reclamados por el interesado. La prizion de este, y ladesu familia fué motivada por una infame calumnia, injustificada entonces, injustificable siempre, por tanto, de producir semejantes procedimientos.

Yo, comprehendí desde luego todasu enormidad, y en el momento deser instruido de ella ocurré respetuosamente al Sõr Delegado dePolícia, como V.E. verá delas copias autenticas que adjunto . $^{\text {OS }} 1,2$ y 3 à efecto de exigir la mitigacion de aquellas penas. Mas, el paso estabadado y no pude conseguir nada, à pesar demi respetuosa intervencion, sobrela cual interpuse mi mediacion, mas bien que mi intervencion directa, y sin darme por ofendido dela faltade cortesia, y á lapar, no habiendo, pues, conseguido nadade este paso conciliatorio, ynosiendo justo, ni siendome posible, en virtud de mis instrucciones Consulares, y de los deberes demi posicion, el dejar indefeso al expresado Sor. Ortiz, subdito de S.M.C., ocurro á V.E. para quesedigne dar sus superiores ordenes á efecto de quesemitigue el vigor adaptado condicho Ciudadano Español, cuya causa ruego á V.E. pidase substancie inmediata y brevemente.

Así lo espero delarectitud é integridad de V.Ex. ${ }^{a}$ cuya vida, Guarde Deos muchos años Vice-Consulado deEspaña en Rio Grande á 5 de Disiembre de1851-Exmo Sor V. Presidente, Don Luis Alves Leite de Oliveira Bello

\section{Pablo de Goycoechea V.Consul.}

\section{IIl.mo Sor.'}

He sido instruido ded el dia 17 del cor.te mes, V. S.a acompañado de una escolta, se presentó en la casa morada del Ciudadano Español D.n Fernando Ortiz, y usando dela autoridad que inviste, arrebató á éste, á su Sra'. Esposa, á su dependiente y una Esclava suya, desu hogar pacifico conduciendo los cuatro á la Carcel publica dellas, quines han sufrido la verguenza y la ingnominia de este paso, y las consequencias que le eran consiquientes.

He sido tambien instruido de que dicho Ciudadano Español protestó en el acto desu prision y exigió se le garantiezen sus intereses, suplicando á V. E. ${ }^{a}$ se dignase providenciar su custodia, dela depredacion. 
$Y$, ultimamente he sido informado, de que el origen que ha motivado este procedimiento es um crimen supuesto, una infame calumnia, cuya creencia ha constituido al Snr. Ortiz aparentemente, y contra toda verosimilitud, en el catalogo delos criminales famosos.

En efecto solo sobre ellos, y bien averiguada preventivamente la certitud desu crimen, es que pudiera recaer la pena que yá ha sufrido el Ciudadano Español, D.n Fernando Ortiz - Digo, que yá ha sufrido pena, porque el acto de prision, con las circunstancias que lo han acompañado, sobre las personas que conjuntamente ha recaidos, y con los demas incidentes que le han seguido respecto dichas personas y sus intereses, es una verdadera pena, aunque nose mirase en ella mas que la nota de infamia, y las consequencias que esta deja ante el Publico para con una familia que siempre la ha tenido por honradas.

Bajo éste solo aspecto, y cercionado dela inculpabilidad de los supuestos reos, encreible me parece, que tal haya sido el procedimiento deV.S.a y mucho mas encreible lo reputo respecto al informe, que se me ha dado sobre los intereses del pretenso criminal Ortiz, pues que ésta negativa no puede nunca tener lugar; y asi es que nole doy credito porque supongo á V.S. ${ }^{a}$ adornado de justicia y de rectitud al cualquer modos, que seos haciendole yo á V.S.a ésta justicia de recto é integro, es que ocurro á la V.S.a para rogarle se digne informarme de este hecho, y del origen que ha podido motivarlo, suplicandole al mismo tiempo, que cualquiera quesea dicho origen se digne mitigar el rigor con que ha sido tratados elmencionado Español Ortiz y su familia cuyos intereses espero estavan custodiados por la autoridad de V. S. ${ }^{a}$ de los cuales V. S.a responderá en devido tiempo.

He procurado siempre guardar una armonia la mas exacta de finura y de politica con las Autoridades del Pais cuando esta han entendido en assuntos concernientes á los subditos de la Nacion á que represento. En éste concepto, pues, le reitero mi exigencia arriba expressada, y al hacerlo, lo saludo con las consideraciones que siempre tributo á todas las Autoridades locales.

Dios Guarde á V. S.a muchos años. Vice Consulado de S. M. Catolica en Rio Grande á 29 de Noviembre de $1851=$ Ill.mo Snr. D.n Alexandre Vieira da Cunha Delegado de Policia de la Ciudad de Pelotas $=$ Pablo de Goycoechea $=$ V. Consul

- Está conforme -

Pablo de Goycoechea

V. Consul 
Accuzo a recepção do seu officio de 29 do passado á cujo conteudo me cumpre responder, que em referencia á prizão e proceso do Cidadão Hespanhol Fernando Ortiz tenho por inoportuna e até inconviniente, que qualquer ingerencia que V.a S.a, sem fundamento algum, nem mesmo nas funções que exerce, pretenda invogarse muito principalm $^{\mathrm{e}}$ nos termos extranhos em que é concebido seu dito officio, porque procedendo na repreção dos crimes e punição de seus autores segundo as Leis do meu Paiz, não me julgo por consideração alguma na obrigação de explicar meus actos aos Snr.s Vice-Consules, quando, como no caso prezente, possa acharse emplicados em crimes algum extrangeiro. Espero q'e V. ${ }^{\mathrm{a}} \mathrm{S} .^{\mathrm{a}}$ tomará como peremptoria esta minha resposta, e independente de ulteriores explicações.

Quanto á providencia sobre os interesses do dito Ortiz si o Snr.' Vice Consul achalá para si que elles sob a guarda, cuidado, e administração aos parentes, e prepostos do mesmo, não estão convenientementeacautellados, então póde, e deve requerer o que julgar da sua obrigação, e neste sentido me achará sempre prompto á fazer justiça á quem ella for devida, sem que por agora me embaraçe com protestos que nada valem.

Deos Guarde á V.a S.a Pelotas 4 de Dezembro de $1851=$ Alexandre Vieira da Cunha - Delegado de Policia do Termo

- Está conforme -

Pablo de Goycoechea

Ill.mo Sor' Alexandre Vieira daCunha

Delegado dePolicia dela Ciudad dePelotas

Acuso recepcion del oficio de V.S.a, data 4 del cor.e mes y, como en el nada satisfase al mio, dirigido á V.S.a con fecha de 29 de Nobre pp. ${ }^{\circ}$; me parece no extrañará deque ocurra á Autoridad Superior los cual pongo en conocimiento deV.S. a á quien tengo el gusto desaludarlo con mi acostumbrada consideracion y aprecio.

Dios Guarde á V. S.a muchos años.

Vice Consulado deEspaña, en Rio Grande a 5 de Diciembre de 1851. = Pablo de Goycoechea - Vice-Consul

Está conforme

Pablo de Goycoechea

V. Consul 
Siento profundamente tener que ser importuno molestando la venerada atencion de V. E. incluyendo adjunto copia de mi último oficio á V. E. data 5 de Diciembre del que vá á finar; y las notas que se han cruzado entre este Vice Consulado de S.M.C. y el Snr. Delegado de Policia de Pelotas a respecto de la prision de que todavia sufre el Ciudadano Español, D.n Fernando Ortiz y gime á la vez, la familia en la Carcel publica de dicha Ciudad, sin que este todabia substanciada el proceso.

Desagradable, es, al que subscrebe Ex.mo Sor.; el motivo de pedir nuevamente justicia, y nada mas que justicia, sobre el hecho praticado por aquel Sor. Delegado; y sin ondar suceso tan injustificable del cual V.E., me parece estará enterado; el abajo firmado como Vice Consul de S.M.Catolica, vuelve á suplicar á V.E., se digne mandar dictar-orden, se evacue el tegido de falsedo des, acumulados al referido Ortiz.

Saludo con aprecio á V. Ex.a á quien Dios Guarde de muchos años $=$ Vice Consulado de España en Rio Grande á 30 de Diciembre de 1851.

Ill.mo é Ex.mo Sor.'Vice Presidente de la Provincia

D. ${ }^{\mathrm{n}}$ Luis Alves Leite de Oliveira Bello

Pablo de Goycoechea

Vice Consul

Ill.mo Snr?

He sido instruido de que el dia 17 del corriente mes, V.S.a acompañado de una escolta, se presentó enla casa morada de Ciudadano Español D.n Fernando Ortiz, y, usando dela autoridad que inviste, arrebató á éste, á su Sra. Esposa, á su dependiente y una esclava suya, desu hogar pacifico conduciendo los quatro á la Carcel publica de eso, quienes han sufrido la vergüenza y la ignominia de este paso, y las consequencias que le eran consiguintes.

He sido tambien instruido de que decho Ciudadano Español protesto en el acto de su prision, y exigió sele garantiesen sus intereses, suplicando á V. S.a se dignase providenciar su custodia, dela depredacion.

$\mathrm{Y}$, ultemamente he sido informado, de que el origen que ha motevado este procedimiento es un crimen supuesto, una infame calumnia, cuya creencia ha constituido al Snr. Ortiz aparentemente, y contra toda verosimilitud en el catalogo delos criminales famosos.

En efecto $=$ solos sobre elos, $\mathrm{y}$ bien averigüada preventivamente la certitud de su crimen, es que pudiera recaer la pena q. ${ }^{e}$ yá, ha sufrido el Ciudadano Español D. ${ }^{n}$ Fernando Ortiz - Digo, que yá ha sufrido pena, porque el acto de prision, con las circunstancias q. ${ }^{e}$ los han acompañado, sobre las personas q. ${ }^{e}$ conjuntamente ha recaidos, y conlos demas incidentes que le han seguido respecto dechas personas y sus intereses, es 
una verdadera pena, aunque nose mirase en ella mas que la nota de infamia, y las consequencias que esta deja ante el Publico para conuna familia que siempre laha tenido por honrada.

Bajo éste solo aspecto, y cercionado dela inculpabilidad delos supuestos reos, encreible me parece, que tal haya sido el procedimiento de V. S. ${ }^{\mathrm{a}}$, y mucho mas encreible lo reputo respecto al informe, que se me ha dado sobre los intereses del pretenso criminal Ortiz, pues que ésta negativa nopuede nunca tener lugar; y asi es que nole doy credito, porque supongo á V.S. ${ }^{\mathrm{a}}$ adornado de justicia y de rectitud. De cualquier modo q. ${ }^{\mathrm{e}}$ sea, haciendole yo, á V.S. ${ }^{a}$ esta justicia de recto é integro, es que ocuno á V.S.a para rogarle se digne informarme de este hecho, y del origen que ha podido motivarlo, suplicandole al mismo tiempo, que cualquiera que sea diecho origen, se digne mitigar el rigor con que han sido tratados el mencionado Español Ortiz y su familia, cuyos intereses espero estavan custodiados por la autoridad de V.S. ${ }^{\mathrm{a}}$ de los cuales V.S. ${ }^{\mathrm{a}}$ responderá en devido tiempo.

He procurado siempre guardar una armonia la mas exacta de finura y de politica con las Autoridades del Pais cuando estas han entendido en assuntos concernientes á los subditos de la Nacion á que represento. En éste concepto, pues, le reitero mi exigencia arriba expresada, y al hacerlo, lo saludo con las consideraciones que siempre tributo á todas las Autoridades locales.

Dios Guarde á V.S. ${ }^{\mathrm{a}}$ muchos años.

Vice Consulado de S.M.Catolica en Rio Grande á 29 de Noviembre de $1851=$ Ill. ${ }^{\text {mo }}$ Sñr. D. ${ }^{\mathrm{n}}$ Alexandre Vieira da Cunha Delegado de Policia dela Ciudad de Pelotas $=$ Pablo de Goycoechea $=$ Vice Consul $=$

\section{/ Esta conforme $=$ Pablo de Goycoechea \\ - Vice Consul}

$$
\text { Ex. }{ }^{\mathrm{mo}} \text { Sor. }
$$

El subdito de S.M.Catolica, Fernando Ortiz, vecino y del comercio de la Ciudad de Pelotas, fué violentamente arrebatado desu casa, por orden de Ill. mo Sor̃. Delegado de Policia, consu Esposa, un dependiente y una esclava suya y llevados todos á la Carcel publica de deicha, Ciudad, en medio del dia, y á la faz de todo el Mundo con vejamen desu reputación y con perjuicio irreparable de sus intereses, los cuales no parecen garantidos por deicha Autoridad y q. ${ }^{\mathrm{e}}$ fueron ambas cosas reclamadas por el interesado. La pricion de éste, y la de su familia fue motivada por una infame calumnia, injustificada entonces, injustificable siempre, por tanto, de producir semejantes procedimientos.

Yó, comprehende desde luego toda su enormidad, y en el momento de ser instruido de ella ocurre respectivamente al expresado Sor. Delegado de Policia, como verá V.E. delas copias autenticas que adjunto N. ${ }^{0} 1,2$ y 3 á afecto de exigir la mitigacion de aquellas penas. Mas, el paso estaba dado y no pude conseguir nada, á pesar de mi respetuosa intervencion sobre la cual interpuse mi mediacion, mas bien que mi 
intervencion directa, y sin darme por ofendido delafalta de cortesia, y á la par, no habiendo, pues, conseguido nada de éste paso conciliatorio, y no siendo justo, ni siendome posible, en virtud de mais instrucciones Consulares, y delos deberes de mi posicion, el dejar indefenso al espresado Sor. Ortiz, subdito de S.M.C., veunos á V.E. para que se digne dar sus Superiores ordenes á efecto de que semitigue el rigor adoptado condicho Ciudadano Español cuya causa ruego á V.E. peda se substancie inmediata y brevemente.

Asi lo espero dela rectud é integridad de V.E. cuya vida Guarde Dios muchos años $=$ Vice Consulado de España en Rio Grande 5 de Diciembre de $1851=$

Ex. ${ }^{\text {mo }}$ Sor. Vice Presidente, D. ${ }^{\mathrm{n}}$ Luis Alves Leite de Oliveira Bello.

Está conforme -

Pablo de Goycoechea

V.Consul

Anexo 2 - documento de 30 de dezemóro de 1851.

\section{Ill. ${ }^{\text {mo }}$ Sñr Pablo de Goycoechea}

Acuzo a recepção do seu officio de 29 do passado á cujo conteudo me cumpre responder, que emreferencia a prizão e processo do cidadão Hespanhol Fernando Ortiz, tenho por inoportuna e até inconveniente, que qualquer ingerencias que V. S. ${ }^{\mathrm{a}}$, sem fundamento algum, nem mesmo nas funções que exerce, pretenda arrogar-se muito principalm. $^{\mathrm{e}}$ nos termos extranhos em que é concebido seu dito officio porque procedendo na repreção dos crimes e punição de seus auctores segundo as Leis do meu Paiz, não me julgo por consideração alguma na obrigação de explicar meus actos aos Snr. ${ }^{\text {S }}$ Vice-Consules, quando, como nocaso prezente, possa achar-se implicados em crimes algum extrangeiro Espero que V. ${ }^{\mathrm{a}} \mathrm{S} .{ }^{\mathrm{a}}$ tomará como peremptoria esta minha resposta, e independente de ulteriores explicações.

Quanto a providencia sobre os interesses do dito Ortiz, si o Sñr Vice Consul acha la para si que elles sob a guarda, cuidado, e administração dos parentes e prepostos do mesmo, não estão convenientemente acautellados, então póde e deve requerer o que julgar da sua obrigação, e neste sentido ma achará sempre prompto à fazer justiça à quem ella for devida, sem que por agora me embarace com protestos que nada valem. Deos guarde a V. ${ }^{\mathrm{a}} \mathrm{S} .{ }^{\mathrm{a}}$ Pelotas 4 de Dezembro de 1851

Alexandre Vieira da Cunha - Delegado de Policia do termo = Está conforme $=$ Pablo de Goycoechea 
Delegado de Policia dela Ciudad de Pelotas.

IIl. ${ }^{\text {mo }}$ Sor.Alexandre Vieira da Cunha,

Acuso recepcion del Oficio de V.S. ${ }^{\text {a }}$ data 4 del corr. ${ }^{\text {te }}$ mes, y, como en el nada satisfaze al mio dirigido á V.S. ${ }^{a}$, confecha de 29 de noviembre pp. ${ }^{\circ}$ me parece no estranará de que ocurra á Autoridad Superior lo que pongo en conocimiento V.S. ${ }^{a}$ á quien tengo el gusto de saludarlo con mi acostumbrada consideracion y aprecio.

Dios Guarde á V. S. ${ }^{a}$ muchos años. Vice Consulado de España, en Rio Grande á 5 de Diciembre de $1851=$

\section{Está conforme}

Pablo de Goycoechea

V. Consul

\section{$\operatorname{Ilm}^{\circ}$ e Ex ${ }^{\mathrm{mo}}$ Sen $\tilde{r}$}

Dabaixo assignado Vice Consul de S. M Catholica nesta Cidade tem a Honra de participar a V. Ex. ${ }^{\text {cia }}$ ser-lhe precizo fazer em 30 de outubro do anno ppassado, acabo agora de assumir seu competente exercicio do qual durante sua auzencia havia ficado encarregado o Chanceller de S. M Fidellissima Antonio Maria do Amaral Ribeiro, tudo em

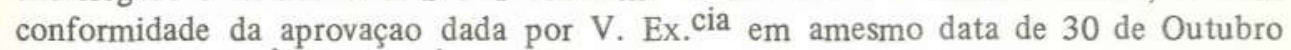
ppassado Deos G. ${ }^{\text {de }}$ a V. Ex. ${ }^{\text {cia }}$ muitos annos.

Vice Consulado de S. M. Catholica em Porto Alegre 10 de janeiro de 1852.

$$
\begin{gathered}
\text { Illm. }{ }^{\circ} \text { e Ex. }{ }^{\text {mo }} \text { Senr D }{ }^{\text {or }} \text { Luiz Alves Leite } \\
\text { de Oliveira Bello } \\
\text { Dign. }{ }^{\circ} \text { Vice Preside da Pron cia } \\
\text { João Pereira Machado } \\
\text { Vice Consul }
\end{gathered}
$$

(Documentos constantes da lata n. ${ }^{\circ} 183$ do Arquivo Histórico do Rio Grande do Sul.) 